the European Ceramic Society

Elsevier Editorial System(tm) for Journal of Manuscript Draft

Manuscript Number: JECS-D-18-01933R5

Title: SEMICONDUCTOR WATER-BASED INKS: MINIATURIZED NiO PSEUDOCAPACITOR ELECTRODES BY INKJET PRINTING

Article Type: Full Length Article

Keywords: Water-based inks; Ceramic semiconductor; Inkjet printing; Path design; Miniaturized pseudocapacitor electrodes

Corresponding Author: Mr. Joaquin Yus, M.D.

Corresponding Author's Institution: Instituto de Ceramica y Vidrio. CSIC

First Author: Joaquin Yus, M.D.

Order of Authors: Joaquin Yus, M.D.; Zoilo Gonzalez, PhD; Antonio Javier Sanchez-Herencia, PhD; Alex Sangiorgi, PhD; Nicola Sangiorgi, PhD; Davide Gardini, PhD; Alessandra Sanson, PhD; Carmen Galassi, Professor; Alvaro Caballero, Professor; Julian Morales, Professor; Begoña Ferrari, PhD

Abstract: The formulation, development and optimization of water-based inks of platelet-like nanoparticles are the main objective of this work. As-synthesized $\mathrm{Ni}(\mathrm{OH}) 2$ nanoparticles were dispersed and stabilized in aqueous suspension by PEI addition. The combination of DEG (cosolvent) with H2O shows the ideal values of surface tension and viscosity for piezoelectric inkjet printing, which exhibits a homogeneous jetting flow of the nanoplatelets suspension. The printed nanostructure was sintered at low temperature (325 $\square$ C) and the electrochemical overview of NiO electrode behavior was described. These printable pseudocapacitors tested by a three-electrode cell have showed a competitive specific capacitance, leading $92 \%$ and $78 \%$ of capacitance retention for 2000 cycles at scan rates of 1 and $2 \mathrm{~A} / \mathrm{g}$ respectively, and a coulombic efficiency of $100 \%$. The initial performance of this printed NiO pseudocapacitor can be compared with others prepared by conventional methods. This new finding is expected to be particularly useful for the designing of micropseudocapacitors. 


\section{${ }^{*}$ Detailed Response to Reviewer Comments}

\section{Dear Editor,}

Thank you very much for your response and the reviewer and editor comments on our paper JECSD-18-01933R2 entitled "Semiconductor Water-based Inks: Miniaturized NiO Pseudocapacitor Electrodes by Inkjet Printing”, J. Yus, Z. Gonzalez, A.J. Sanchez-Herencia, A. Sangiorgi, N. Sangiorgi, D. Gardini, A. Sanson, C. Galassi, A. Caballero, J. Morales and B. Ferrari, whose research has been supported by the European Ceramic Society through a JECS TRUST mobility grant (Contract number: 2017141).

Related to the last received comments:

The authors have now explained the changes from the previous version but it is clear that the reduction in size of the manuscript is minimal - blank lines between paragraphs have been removed and some figures have been reduced in size. There has been no real attempt to reduce the size of the manuscript. The authors are given one final opportunity to address the following outstanding problems:

(i) All the text needs to be checked very carefully and corrected. There are still numerous grammatical errors.

(ii) The introduction and the Results and Discussion sections are still very long for the work reported. There is significant scope to reduce the text and if required to move more figures (or parts of figures) to Supplementary Information.

Please obtain the help of a senior researcher for the revisions.

The authors will need to explain in detail what specific changes they have made - it is not sufficient to say that the text has been reduced.

The manuscript has been corrected by most of the senior co-authors in its different versions. Mainly by: D. Gardini, A. Sanson, C. Galassi, B. Ferrari. I have been properly revising the last version (manuscript highlighted R5) of the manuscript myself (B. Ferrari) and this is why I am signed the cover letter (below). I corrected the English up to my knowledge.

We are submitting the "word version with changes highlighted" (manuscript highlighted R5) to demonstrate the full correction of the text in all the sections. I tried to improve the edition of a couple of figures and also I removed some micrographs in figures 4 (b-c) and 5 (g-i). Additionally, I reduced the number of pages of the whole text with respect to the first version (form 23 to 16 pages), following the reviewer's suggestions. Notice that the tittle has also been reduced and some references removed.

A detailed descriptive of the inks preparation and 2D printing, which avoids defects, supports the first paragraph of conclusions (figures 1 and 2), demonstrating that if the ink is optimized one layer pattern is enough to achieve expected density and consolidation after the thermal treatment (figures 
3 to 5). This is why we think all the current results showed in this version R5 determine the final electrochemical performance (Figure 6).

We hope to have satisfactorily fulfilled all the requirements and look forward to hear from you soon. Sincerely,

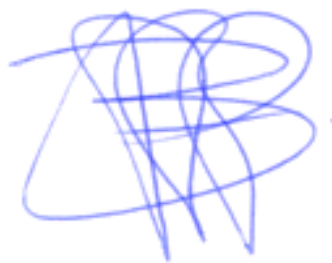

Dr. Begoña Ferrari

Tenured Scientist

Instituto de Ceramica y Vidrio, CSIC

Data of the corresponding author are:

Joaquin Yus

Instituto de Cerámica y Vidrio (ICV). CSIC

5 Kelsen Street. 28049, Madrid, Spain

email: joaquinluis.yus@icv.csic.es 


\title{
SEMICONDUCTOR WATER-BASED INKS: MINIATURIZED NiO PSEUDOCAPACITOR ELECTRODES BY INKJET PRINTING.
}

\author{
J. Yus $^{1 *}$, Z. Gonzalez ${ }^{1}$, A.J. Sanchez-Herencia ${ }^{1}$, A. Sangiorgi ${ }^{2}$, N. Sangiorgi ${ }^{2}$, D. \\ Gardini $^{2}$, A. Sanson ${ }^{2}$, C. Galassi ${ }^{2}$, A. Caballero ${ }^{3}$, J. Morales ${ }^{3}$, B. Ferrari ${ }^{1}$ \\ ${ }^{1}$ Instituto de Cerámica y Vidrio, CSIC, Madrid, Spain \\ ${ }^{2}$ Institute of Science and Technology for Ceramics, CNR, Faenza, Italy \\ ${ }^{3}$ Departamento de Química Inorgánica, Universidad de Córdoba, Spain
}

\section{Abstract}

The formulation, development and optimization of water-based inks of platelet-like nanoparticles are the main objective of this work. As-synthesized $\mathrm{Ni}(\mathrm{OH})_{2}$ nanoparticles were dispersed and stabilized in aqueous suspension by PEI addition. The combination of DEG (cosolvent) with $\mathrm{H}_{2} \mathrm{O}$ shows the ideal values of surface tension and viscosity for piezoelectric inkjet printing, which exhibits a homogeneous jetting flow of the nanoplatelets suspension. The printed nanostructure was sintered at low temperature $\left(325^{\circ} \mathrm{C}\right)$ and the electrochemical overview of $\mathrm{NiO}$ electrode behavior was described. These printable pseudocapacitors tested by a three-electrode cell have showed a competitive specific capacitance, leading $92 \%$ and $78 \%$ of capacitance retention for 2000 cycles at scan rates of 1 and $2 \mathrm{~A} / \mathrm{g}$ respectively, and a coulombic efficiency of $100 \%$. The initial performance of this printed $\mathrm{NiO}$ pseudocapacitor can be compared with others prepared by conventional methods. This new finding is expected to be particularly useful for the designing of micropseudocapacitors. 


\section{Introduction}

The development of InkJet Printing technology (IJP) has exponentially grown during the last few years, especially in ceramic decoration [1]. Recently, IJP of semiconductor ceramic compounds in the manufacture of miniaturized devices and other industrial applications, such as microchips, home printers, LCD and plasma screens, etc., has led to the development of novel and innovative functional inks [2-4]. IJP consists in the deposition of suspensions or inks on a substrate following the path designed by the 2D or 3D modelling software. Although it is mainly a 2D technique, layer-by-layer printing can be also employed in order to increase the pattern thickness. Among the advantages of this technique there are the exhaustive control over the amount of deposited material, the high precision in the patterns design or the elimination of unwanted waste. In this sense, the IJP is considered an un-expensive processing technique easy to be adapted for mass production of customized products.

IJP patterns result from the combined effects of the ink flowing properties, the heads technology of the printer and the ink-substrate interaction during deposition and drying. In commercial piezoelectric printers the nozzle diameter changes with the applicationlt is well known that smaller nozzles allow smaller droplets and higher resolutions, and it is generally accepted that particle size should be 50 times lower than the diameter of the nozzle to avoid clogging [5]. Homogeneously dispersed nanoparticles will ensure the accuracy, while a good jetting and drying feature is required to obtain clear profiles and to keep the desired functionality of the inks.

The solvent must carry the nanoparticles in suspension until printing, and then it should evaporate at the prefixed drying rates. In order to optimize the formulations of the inks, the combination of solvents and the use of additives is widely spread [6-8]. Wetting and drying behavior, the drop formation and the successful jetting, are the most relevant characteristics of the inks in this process. Organic solvents provide low values of surface tension and reduce the interactions among particles, promoting lower viscosities and Newtonian behaviors [9]. However, due to the need to substitute organic inks with water based ones [10] the selection of solvents and additives providing the inks with ideal properties is extremely relevant in water-based inks. Printable aqueous inks require viscosities in the range of 2-20 mPa.s and Newtonian behavior. The behaviour of water-based suspensions is normally non-Newtonian, typically pseudoplastic. Because inkjet printers operate in the frequency range of $1-10 \mathrm{kHz}$, the strain rates are expected to be in the range $10^{3}-10^{4} 1 / \mathrm{s}$, and it is difficult to measure the fluid viscosity in this range of shear rates [11]. However, applying the Cross model to the thinning or pseudoplastic behaviour allows extrapolating the viscosity for an infinite shear rate. 
On the other hand, the surface tension has to be high enough to keep the suspension in the nozzle and avoid premature drop generation, and low enough to enable the spread of the drop onto the substrate surface. The use of cosolvents, in particular water, helps to reduce the evaporation rate of solvent mix and provides proper values of surface tension and viscosity [12]. In particular, glycol as water cosolvent is widely employed in the literature $[2,12,13]$. This solvent is used as a humectant to minimize drying at the printer nozzles [2] as well.

The surface tension and viscosity can be regarded as the key physical parameters to optimize the quality of jetting and deposition. Both parameters are related by the $Z$ parameter which is the inverse of the Ohnesorge number. This number is defined by the equation:

$$
Z=\frac{1}{O h}=\frac{R e}{\sqrt{W e}}=\frac{\sqrt{\gamma \rho a}}{\eta}
$$

where $O h$ is the Ohnesorge number, $R e$ is the Reynolds number and We is the Weber number. $\gamma(N \cdot m), \eta(\mathrm{mPa} \cdot \mathrm{s})$ and $\rho\left(\mathrm{g} / \mathrm{cm}^{3}\right)$ are the surface tension, the viscosity and the density of the ink, respectively, and $a(\mathrm{~nm})$ is the diameter of the nozzle.

This non-dimensional parameter is used in the literature to predict a successful ejection. Commonly $1<Z<10$ is considered the optimal range [14,15]; Yang et al. [16] defined the printable range as $4 \leq Z \leq 14$, while for other authors, such as Mogalicherla et al. [17], this parameter does not seem really relevant.

Regarding to energy storage devices, IJP meets the challenges involved in printing the electrodes, interconnections and contacts by reducing electrical lossDelannoy et al.[18] and Gu et al. [19] developed $\mathrm{LiFePO}_{4}$ water-based inks for jetting, achieving similar discharge capacities and cyclability features (150 and $130 \mathrm{mAh} / \mathrm{g}$ ) for patterns 4 and $20 \mu \mathrm{m}$ thick, printed onto aluminum and CNT mats.

Carbonaceous materials, especially graphene-based inks, were also printed and characterized.

Usually pseudocapacitors are made by transition metal oxides (TMO's) or conducting polymers as a functional material. TMOs have a high electrical conduction and accumulate the energy through redox reactions. Among others TMO's, NiO nanoparticles (NPs) inks have been proposed for the manufacture of different electronic devices. Lee et al. [12] first reported the $\mathrm{Ni}$ electrode fabrication by laser direct writing of $\mathrm{NiO}$ ink, while $\mathrm{Li}$ et al. [20] utilized a multi-color desktop inkjet printer to print $\mathrm{Ni}$ electrodes, and more recently, Huang et al. [21] reported inkjet-printed $\mathrm{NiO}$ films for its application as a thermistor. Finally, Rho et 
al. [22] have developed an inkjet-printable $\mathrm{NiO}$ ink containing precrystallized ultra-small $\mathrm{NPs}$, evidencing an arbitrary patterning of $\mathrm{NiO}$ electrodes.

In our work, as-synthetized $\mathrm{Ni}(\mathrm{OH})_{2}$ plate-like NPs were used to formulate a water-based ink used to prepare miniaturized pseudocapacitor electrodes based on ceramic semiconductors. The ink formulation was optimized in terms of viscosity, surface tension and particle size to achieve printable compositions with high level of reproducibility. In addition, the printer parameters (frequency, voltage, pulse, etc.) were adjusted to reach homogeneous patterns deposition with a high accuracy. The microstructural properties of these patterns onto $\mathrm{Ni}$ foils were also analyzed by FESEM and the optimized designs were sintered at $325^{\circ} \mathrm{C}$ under $\mathrm{N}_{2}$ atmosphere to consolidate the $\mathrm{NiO}$ porous nanostructure. Finally, the electrochemical behavior of the developed electrodes was tested by different techniques, such as cyclic voltammetry and chronopontentiometry.

\section{Experimental}

All chemicals were of reagent grade and employed without any further purification. The $\beta$ $\mathrm{Ni}(\mathrm{OH})_{2}$ nanoplatelets used for the inks formulations were synthetized by a chemical precipitation route, assisted by ultrasound, which has been described elsewhere $[23,24]$. The ultrasonic horn used was Sonopuls HD $2200\left(45 \mathrm{~W} / \mathrm{cm}^{2}, 24 \mathrm{kHz}\right.$, Bandelin Electronic, Germany) with a $\mathrm{Ti}$ tip. The as-synthetized $\mathrm{Ni}(\mathrm{OH})_{2}$ nanoparticles were dispersed in a mixture of diethylene glycol (DEG) and water 1:1. 2.5\%wt. (respect to the weight of $\left.\mathrm{Ni}(\mathrm{OH})_{2}\right)$ polyethylenimine (PEI) was added as deflocculant in and the $\mathrm{pH}$ of the suspension was adjusted at 10. Then, the suspension was ball-milled for 2-36 $\mathrm{h}$ in order to break agglomerates and homogenize the inks. Part of this suspension was diluted down to 0.1 $\mathrm{g} / \mathrm{L}$ in 1:1 DEG: $\mathrm{H}_{2} \mathrm{O}$ at $\mathrm{pH} 10$ to determine the zeta potential in a Zetasizer Nano ZS (Malvern Instruments Ltd., Malvern, UK).

The rheology of the solvent and the as-prepared inks with solid content ranging from 10 wt.\% to 25 wt.\% was studied. A Bohlin C-VOR viscometer (Malvern Instruments) with coaxial cylinders (C25) with bob of $25 \mathrm{~mm}$ of diameter and gap $1.25 \mathrm{~mm}$ (the height of the bob is $37.5 \mathrm{~mm}$ ) was used. Tests were performed with a pre-shear in a control rate mode (CR) from 0 to 1000 1/s in 2 min, dwelling at 1000 1/s for 2 min and shearing down to 0 in 2 min. And control stress from $0 \mathrm{~Pa}$ to the values obtained in the previous control rate in 2 min and down back to $0 \mathrm{~Pa}$ in the same time. All tests were done at a constant temperature of $25 \pm 0.5^{\circ} \mathrm{C}$. The applied high-shear rates during up-ramps are enough to achieve a reproducible suspension microstructure, and consider the same starting point to compare the inks formulations. Hence the plotted curves in the rheology study were the down-ramps, 
and the log-log plot was fitted following the Cross model (equation 2) in order to extrapolate the main parameters of the behavior of the inks flux. Cross model is:

$$
\eta=\eta_{\infty} \frac{\eta_{0}-\eta_{\infty}}{1+C_{\dot{\gamma}}^{n}}
$$

where $\eta_{0}$ (mPa.s) and $\eta_{\infty}(\mathrm{mPa} \cdot \mathrm{s})$ are the the viscosities extrapolated at rest and at high shear rates respectively, $C \dot{\gamma}$ is a time constant and $n$ is the rate constant, a parameter related to the viscosity dependence on the shear rate. The Cross model describes the limit behavior of the suspension (viscosity at rest), and at an infinite shear rate which could be equivalent to the ink viscosity when it is jetted through the nozzle.

In addition, it has been found that the Krieger Dougherty Model (K-D) provides a semiempirical correlation of the effective viscosity with the maximum packing volume fraction of solid-liquid suspensions as follows [25]:

$$
\eta=\eta_{s}\left(1-\frac{\phi}{\phi_{m}}\right)^{-n}
$$

where $\phi_{m}$ is the maximum packing fraction, $n$ is an empirical exponent and $\eta_{s}$ is the viscosity of the solvent (mPa.s). The exponent $n$ and the maximum packing fraction, $\phi_{m}$, for the suspension were estimated by using the $\mathrm{K}-\mathrm{D}$ equation.

The $\mathrm{Ni}(\mathrm{OH})_{2}$ nanoplatelets and aggregate sizes in suspension were evaluated in terms of volume fraction. A Zetasizer Nano ZS (Malvern Instruments Ltd., Malvern, UK) was used in order to determine the particle size in a diluted suspension of $\mathrm{H}_{2} \mathrm{O}: \mathrm{DEG}(1: 1)$, using Dynamic Light Scattering (DLS). The inks were filtered in three steps with a 5.0, 1.2 and $0.8 \mu \mathrm{m}$ Minisart $\AA^{\circledR}$ filters in order to avoid clogging of the nozzle. The thermogravimetric (TG) analysis of the inks was carried out from room temperature until $300^{\circ} \mathrm{C}$ at a heating rate of $5^{\circ} \mathrm{C} / \mathrm{min}$ in a simultaneous thermal analyzer (STA 449, Netzsch, Geraetebau).

The surface tension of the $\mathrm{Ni}(\mathrm{OH})_{2}$ inks were measured at ambient conditions using a Drop Shape Analyzer - DSA30 Tensiometer (Krüss) in pendant drop configuration system. In addition, the suspension density was also obtained by measuring the mass of $10 \mathrm{~mL}$ of suspension with a graduate test tube and a microbalance. The average density of the suspension was determined after five different measures being $1.1 \mathrm{~g} / \mathrm{ml}$.

The $\mathrm{Ni}$ foils $(0.2 \mathrm{~mm}$ thick, $99.0 \%$ purity, Goodfellow) were used as substrates and they were cleaned with acetone and ethanol several times using an ultrasonic bath (15 s) and dried prior to print. The $\mathrm{Ni}(\mathrm{OH})_{2}$ ink was then printed directly onto the $\mathrm{Ni}$ foil forming different patterns of $1 \mathrm{~cm}^{2}$. A commercial XCEL System Aurel work cell printer (AUREL 
Automation) was used to print the ceramic ink. This inkjet printer uses piezoelectric actuation, the nozzle diameter is $70 \mu \mathrm{m}$ and the storage system is a tank of $5 \mathrm{ml}$, without recirculation. The topography of the surface of the deposition was also studied by 3D reconstructions by Zeta3D ${ }^{\mathrm{TM}}$ Optical Profiler (ZETA), and the morphology of the deposited particles by Field Emission Gun - Scanning Electron Microscopy (FEG-SEM), IIGMA, Zeiss, (Germany). Then, the inkjet-printed $\mathrm{Ni}(\mathrm{OH})_{2}$ electrodes were sintered at $325^{\circ} \mathrm{C}$ for $1 \mathrm{~h}$ under $\mathrm{N}_{2}$ atmosphere according to previous studies [26]. The uniformity and surface morphology of the resulting $\mathrm{NiO}$ electrodes were also characterized by FE-SEM (Hitachi S4700, Japan).

Finally, the electrochemical behavior of the IJP electrodes was evaluated with cyclic voltammetry $(\mathrm{CV})$ at different scan rates, from 2 to $10 \mathrm{mV} / \mathrm{s}$, in a potential window of 0.0 $0.5 \mathrm{~V}$, using a Potentiostat/GalvanostatAutolab (PGSTAT204, Utrecht, Netherlands) in a three-electrodes configuration cell. $\mathrm{A} \mathrm{NiO}$ printed on the $\mathrm{Ni}$ foil was used as working electrode, $\mathrm{Pt}$ foil as counter electrode and $\mathrm{Ag} / \mathrm{AgCl}$ as a reference. The employed electrolyte was $1 \mathrm{M} \mathrm{KOH}$ aqueous solution. The charging/discharging measurements were carried out through chronopotentiometry analysis $(\mathrm{CP})$ at a scan rate of 1 and $2 \mathrm{~A} / \mathrm{g}$ using a multichannel potentiostat-galvanostat system (Arbin BT2000, Arbin Instruments, College Station, TX, USA). From CP measurements, the specific capacitance value was calculated according to equation:

$$
C=\frac{I \cdot \Delta t}{m \cdot \Delta V}
$$

where $C$ is the specific capacitance $(\mathrm{F} / \mathrm{g}), l$ is the discharge current $(\mathrm{A}), \Delta t$ is the discharging time (s), $\Delta V$ is the voltage window $(\mathrm{V})$, and $m$ is the mass $(\mathrm{g})$ of the printed active $\mathrm{NiO}$ material. The $\mathrm{NiO}$ active mass was determined calculating the mass of the $\mathrm{Ni}(\mathrm{OH})_{2}$ patterns, weighting the substrate and the sample before and after the IJP process respectively, and considering the full transformation of $\mathrm{Ni}(\mathrm{OH})_{2}$ into $\mathrm{NiO}$ after the thermal treatment. All measurements were carried out at room temperature.

\section{Results and discussion}

The $\mathrm{Ni}(\mathrm{OH})_{2}$ particles were synthesized by chemical precipitation in aqueous medium with the help of ultrasound [23,24]. The $\mathrm{Ni}(\mathrm{OH})_{2}$ particles are nanoplatelets of $200-300 \mathrm{~nm}$ in diameter with a thickness of $20-30 \mathrm{~nm}$, while the micro and mesoporosity of obtained $\mathrm{NiO}$ nanoplatelets after calcination ranges $2-3 \mathrm{~nm}$ and $40-50 \mathrm{~nm}$, respectively. The chemical and colloidal stabilization of $\mathrm{Ni}(\mathrm{OH})_{2}$ nanoplatelets in water was optimized in previous works $[23,24,27]$ where nanoplatelets dispersion was adjusted by the PEI adsorption. The branched and cationic nature of this polyelectrolyte contribute to develop the electrosteric interaction among $\mathrm{Ni}(\mathrm{OH})_{2}$ nanoplatelets in water. The colloidal stability of the as- 
synthesized nanoplatelets was estimated from the study of the zeta potential evolution with the $\mathrm{pH}$. The isoelectric point (IEP) is at $\mathrm{pH} 8.5$ and the maximum stability was at $\mathrm{pH} 10$ where the zeta potential is $-20 \mathrm{mV}$. At pH 10, the adsorption of $2.5 \mathrm{wt} . \%$ of PEI changes the zeta potential to a positive and higher absolute value $(+50 \mathrm{mV})$ conferring a better stability to the suspension by improving both steric and electrostatic contributions.

In this work, the medium of the suspension consisted in a mixture of $\mathrm{H}_{2} \mathrm{O}$ and DEG (1:1 vol.). The flux curve of this solvent was also determined, showing a Newtonian behavior and viscosity of $4 \mathrm{mPa} \cdot \mathrm{s}$. The dielectric constant (55.1) was calculated by the Law of Mixtures, considering that $\mathrm{H}_{2} \mathrm{O}$ and DEG have dielectric constants of 78.5 and 31.7, respectively. If compared with water, the higher viscosity and the lower dielectric constant of the $\mathrm{H}_{2} \mathrm{O}$ :DEG mixture limits the electrostatic interaction among particles, slightly decreasing the zeta potential of the suspension of $\mathrm{Ni}(\mathrm{OH})_{2}$ nanoplatelets stabilized with $2.5 \mathrm{wt} . \% \mathrm{PEI}$ to $+42 \mathrm{mV}$.

Different solid contents were tested in the $\mathrm{Ni}(\mathrm{OH})_{2}$ suspensions stabilized with $2.5 \mathrm{wt} . \%$ of $\mathrm{PEI}$ in the $\mathrm{H}_{2} \mathrm{O}$ :DEG solvent. Figure 1a shows the rheograms relating the viscosity of the inks with the shear rate for the $\mathrm{Ni}(\mathrm{OH})_{2}$ suspensions with solid loadings of 10,15 and 20 $w t . \%$. As expected, the increase of solid content effectively increased the viscosity. The viscosity curves clearly show the pseudoplastic behavior of the inks with solid contents of $15 \mathrm{wt} . \%$ and $20 \mathrm{wt} . \%$, while the $10 \mathrm{wt} . \%$ suspension is quasi-newtonian. Figure $1 \mathrm{~b}$ illustrates the K-D approach for the $\mathrm{Ni}(\mathrm{OH})_{2}$ suspensions stabilized with $\mathrm{PEI}$, confirming a maximum packing fraction $\left(\phi_{\mathrm{m}}\right)$ of $7.5 \%$, slightly low due to the high viscosity of the solvent (4 mPa.s) if it is compared with that of the water. The flow curves were also fitted to the Cross model to define the limit behavior of the starting suspension $\left(\eta_{0}\right)$ and at infinite shear rate $\left(\eta_{\infty}\right)$. The table at the inset (Figure 1c) summarizes the values of $\eta_{0}$ and $\eta_{\infty}$ for all the inks. Thinning or pseudoplastic behavior is desirable when the storage system is a tank and suspensions will keep at rest during the printing process. However, if the resting viscosity is very high it will be difficult to start moving the suspension from idle state. In our case the inks prepared at 15 and $20 \mathrm{wt} . \%$ solid contents achieve viscosities at rest exceeding $1 \mathrm{~Pa} \cdot \mathrm{s}$, and for this reason the ink with $10 \mathrm{wt} . \%$ of solid content, showing viscosities of $13-16 \mathrm{mPa} \cdot \mathrm{s}$ in all the shear rate range, was selected for the print test. 
a

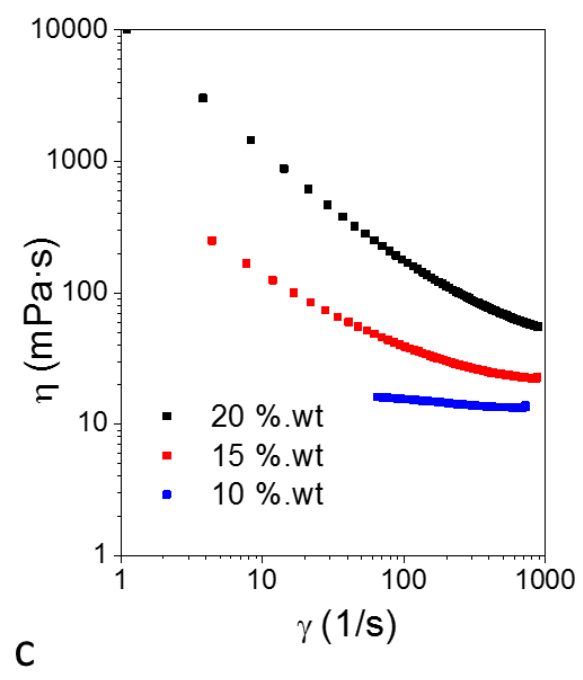

$\%$ wt. $\mathrm{Ni}(\mathrm{OH})_{2} \quad \eta_{0}$ (mPa.s) $\eta_{\infty}$ (mPa.s)

\begin{tabular}{lcc}
\hline $20 \%$ wt. & $3 \mathrm{E} 8$ & 43.9 \\
\hline $15 \%$ wt. & $1 \mathrm{E} 6$ & 18.2 \\
\hline $10 \%$ wt. & 16.1 & 13.5
\end{tabular}

b

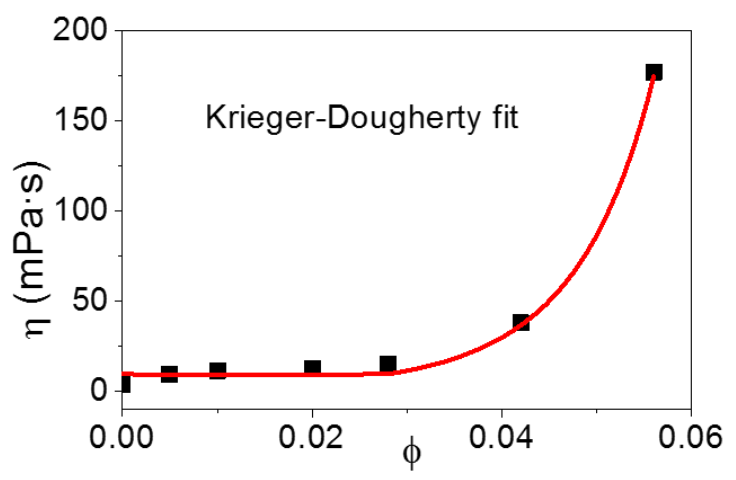

d

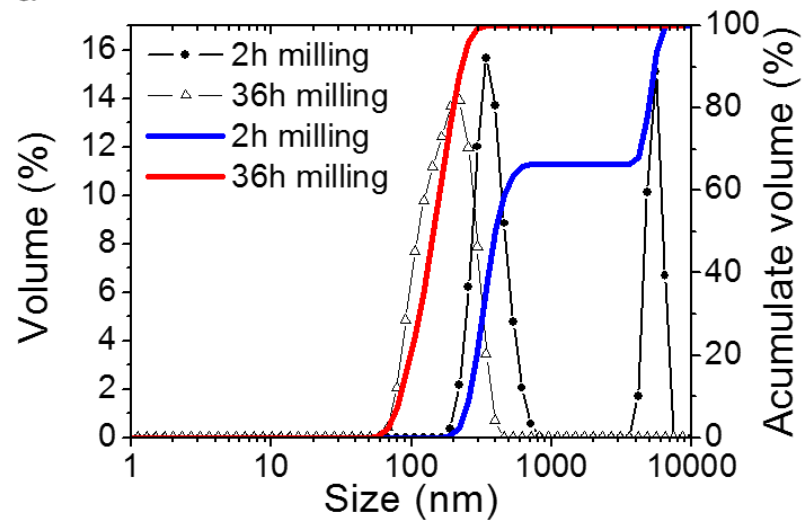

Figure 1. (a) Flow curves and (b) Krieger-Dougherty adjustment of the prepared inks, (c) the summary of the values of the viscosity at rest and at infinite shear rate calculated by equation 2 and, (d) DLS measurements after the 2 and $36 \mathrm{~h}$ ball-milling process

Figure $1 \mathrm{~d}$ shows a bi-modal distribution of particles after $2 \mathrm{~h}$ milling with $5.4 \mu \mathrm{m}$ of the $\mathrm{D}_{\mathrm{v}, 90}$,. After $36 \mathrm{~h}$ milling, the volume size distribution changes into a mono-modal distribution. The aggregates corresponding to the second peak with a mean size of $3000 \mathrm{~nm}$ after the first 2 $\mathrm{h}$ disappears after $36 \mathrm{~h}$ of milling. DLS determination shows that after $36 \mathrm{~h}$ milling, particle size of $\mathrm{Ni}(\mathrm{OH})_{2}$ is below $450 \mathrm{~nm}$, with a large fraction under $200 \mathrm{~nm}(\sim 70 \%$ vol.), while particles size measured by FESEM is 200-300 nm [23]. Differences between both DLS and FESEM measurements are due to the shape of $\mathrm{Ni}(\mathrm{OH})_{2}$, since the measurement by DLS are based on the determination of the diffusion coefficient due to the Brownian movement of the particles, and the radius of the particles is calculated using the Stokes-Einstein equation which assumes that spherical particles have the same diffusion coefficient than the particles in the suspension. Consequently, the values collected in the particle size distribution in Figure 1d can be only considered as an approximation to the real value showed by the FESEM images. 
In any case, it was observed that the particle size after $36 \mathrm{~h}$ milling was not larger than 450 $\mathrm{nm}$, smaller than the minimum required, which is $1400 \mathrm{~nm}$ ( $\sim 50$ times smaller than the nozzle diameter [28]). For this reason, a milling process of $36 \mathrm{~h}$ was fixed for the preparation of this ink. The loss of mass due to the filtration steps was studied by thermal analysis following a heating/cooling schedule of $5 \stackrel{\circ}{\circ} / \mathrm{min}$ until $300^{\circ} \mathrm{C}$. TGA analysis (Figure S1) of the filtered inks shows two mass losses, which take place from 80 to $120^{\circ} \mathrm{C}$ and from 180 to $240^{\circ} \mathrm{C}$ and correspond to the boiling point of the water and DEG, $100^{\circ} \mathrm{C}$ and $245^{\circ} \mathrm{C}$ respectively. The total residual mass is $7 \mathrm{wt} . \%$ that is lower than expected (10 wt.\%) after the evaporation of the solvents. This is because a chemical oxidation reaction takes place during the thermal analysis according to the calcination process of the $\mathrm{Ni}(\mathrm{OH})_{2}$ into $\mathrm{NiO}$. The loss of a molecule of water leads to a nominal mass loss of $30 \mathrm{wt} . \%$ respect to the mass of the hydroxide. This reaction takes place at $250^{\circ} \mathrm{C}$ [24] and it its confirmed by the final black color of the residue of the TGA analysis. This result confirms that no significant amount of solid is retained in the filter and $\mathrm{Ni}(\mathrm{OH})_{2}$ nanoplatelets are fully disperse in the ink.

To verify the applicability of these $\mathrm{Ni}(\mathrm{OH})_{2}$-based inks the $Z$ number was studied. This parameter is calculated by the inverse of the Ohnesorge number, $(Z=1 / \mathrm{Oh})$, and relates the viscosity, density and surface tension parameters. Considering that the viscosity at shear rate infinite is $13.5 \mathrm{mPa} \cdot \mathrm{s}$, the average value of surface tension is $50 \mathrm{mN} / \mathrm{m}$ and the density of the suspension is $1.1 \mathrm{~g} / \mathrm{ml}$, the $Z$ parameter was calculated by the equation (1) resulting in 3 , being within the printable range $[14,15]$.

To avoid macroscopic and microscopic manufacturing defects, which can deteriorate the structural, microstructural, and functional properties of the deposition patterns, and with the objective to define suitable printing conditions, the optimization of the printer parameters was necessary. Figure 2 shows pictures of different defects obtained during the optimization. On one side, the inkjet printing at room conditions produced the coalescence of the ink, forming small drops along the pattern. Figure 2a shows the defects of printing when the substrate was not enough heated or the bed temperature isn't controlled. A temperature of $70 \stackrel{\circ}{ } \mathrm{C}$ was required to maintain in order to get a homogenous path. Nevertheless, an intermediate thermal stabilization steps were also necessary between the sequentially deposited layers. Figure $2 \mathrm{~b}$ illustrates similar defects when the area where the deposition takes place is gradually cooling. For this reason, in Figure $2 b$ the first line shows a single and homogeneous path, while at the second line some defects appeared and the last line presented the most accentuated defects. Additionally, in Figure $2 \mathrm{c}$, the lines were much close and some free spaces were closed by the ink. This problem was related with the diameter of the nozzle, which conditions, to a certain extent, the size of the drop. Moreover, other classical defect, Figure 2d, is due to not adjusted oscillation frequency and 
pulse, producing crooked lines or discontinuities. Finally, a well-defined grid was created by adjusting the frequency, the pulse voltage and the speed movement of the printer head (Table.1). Figure $2 \mathrm{e}$ shows an image of a pattern without defects, where the sizes of the lines and the distance between them were 400 and $300 \mu \mathrm{m}$ respectively.
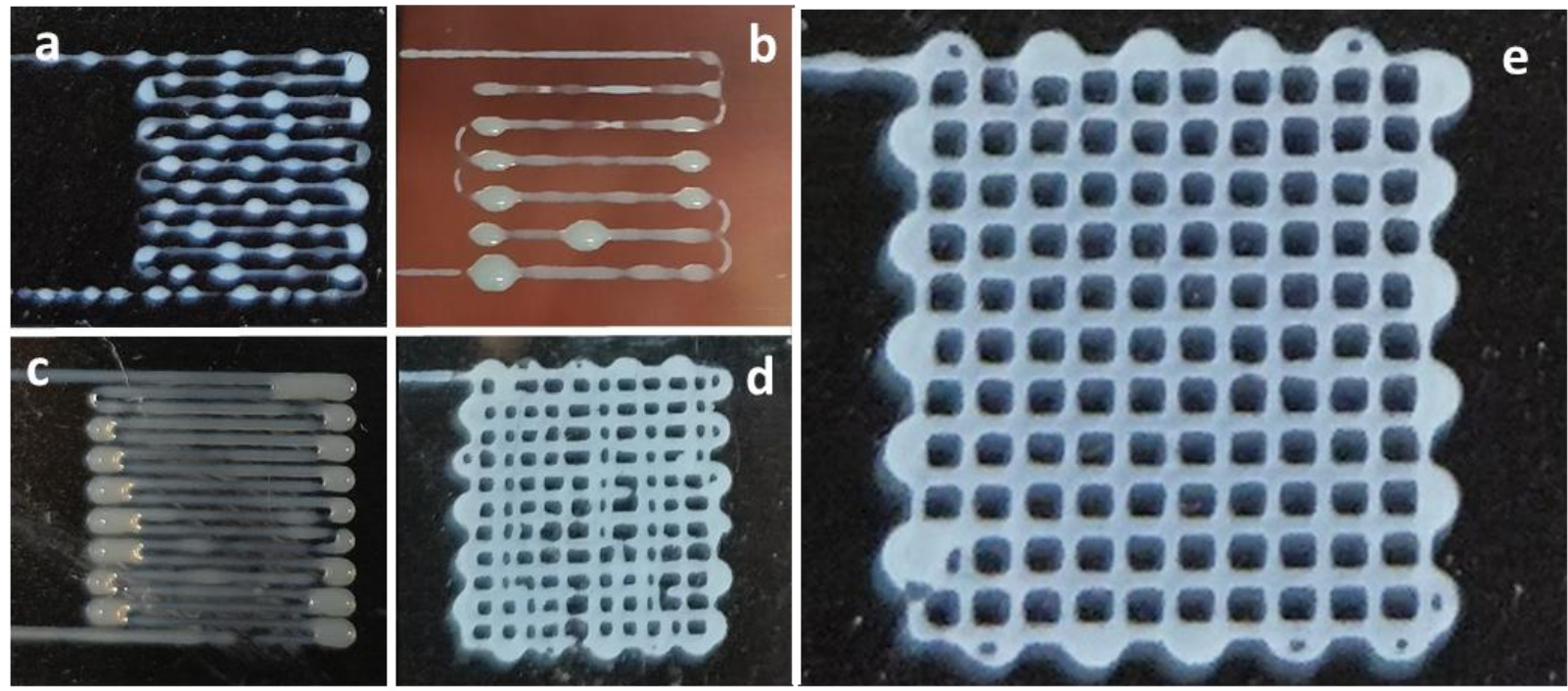

Figure 2. Pictures showing printing defects during the IJP optimization of $1 \mathrm{~cm}^{2}$ patterns

Table 1. Optimized Inkjet parameters

\begin{tabular}{cc}
\hline Ink-Jet parameters & Values \\
\hline Pulse Volt & $230 \mathrm{~V}$ \\
\hline Pulse & $135 \mathrm{us}$ \\
\hline Frequency & $1036 \mathrm{~Hz}$ \\
\hline Strobo Delay & $227 \mathrm{us}$ \\
\hline Pressure & $-20 \mathrm{mBar}$ \\
\hline
\end{tabular}

The size of the printed grid was $1 \mathrm{~cm} \times 1 \mathrm{~cm}$, and the thicknesses were studied in terms of roughness. Figure 3 presents the optical microscopy images of patterns made depositing one layer (Figures $3 a$ and $3 c$ ) and two layers (Figures $3 b$ and $3 d$ ) at different magnifications. Figures $3 e$ and $3 f$ show the $3 \mathrm{D}$ reconstruction of one path for one and two layers samples, respectively. In addition, Figure $3 \mathrm{~g}$ illustrates the Z-height of the printed samples, being $5 \mu \mathrm{m}$ the average height for one layer and $10 \mu \mathrm{m}$ for two layers, and the maximum values 6.8 and $12.9 \mu \mathrm{m}$, respectively. In addition, the diameter of the printed lines ranges $400-480 \mu \mathrm{m}$, following a uniform pattern. Looking at the same figure, the well-known coffee stain effect is slightly perceived. This phenomenon was explained by Deegan et al. [29], who observed that the solute distribution after the drying was strongly influenced by the evaporation process of the solvent. 

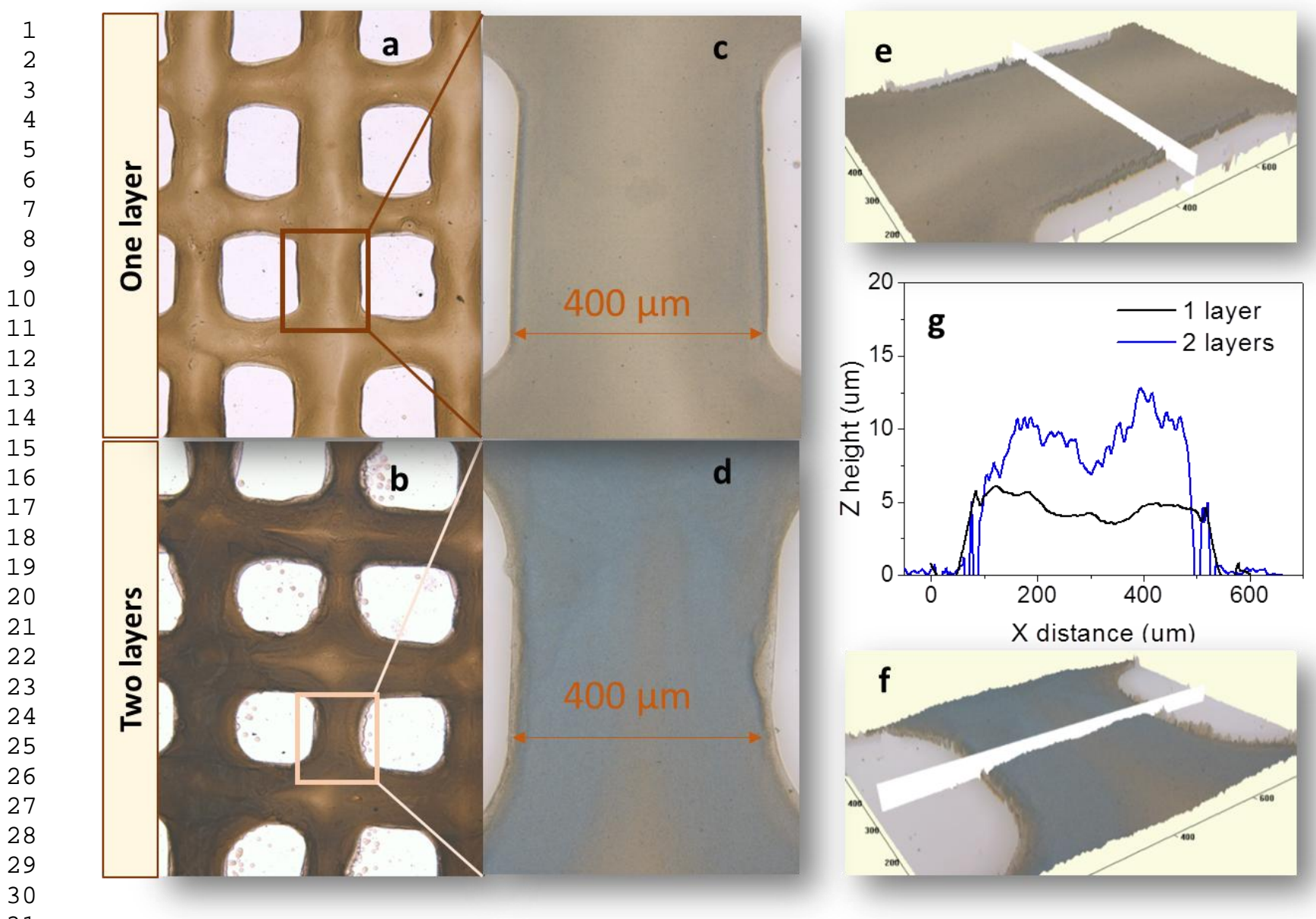

Figure 3. (a-d) Optical microscopy images of the top view of the deposited one and two layers patterns, (e-f) their 3D reconstruction of the cross section and, $(g)$ the height of one and two layers patterns. 

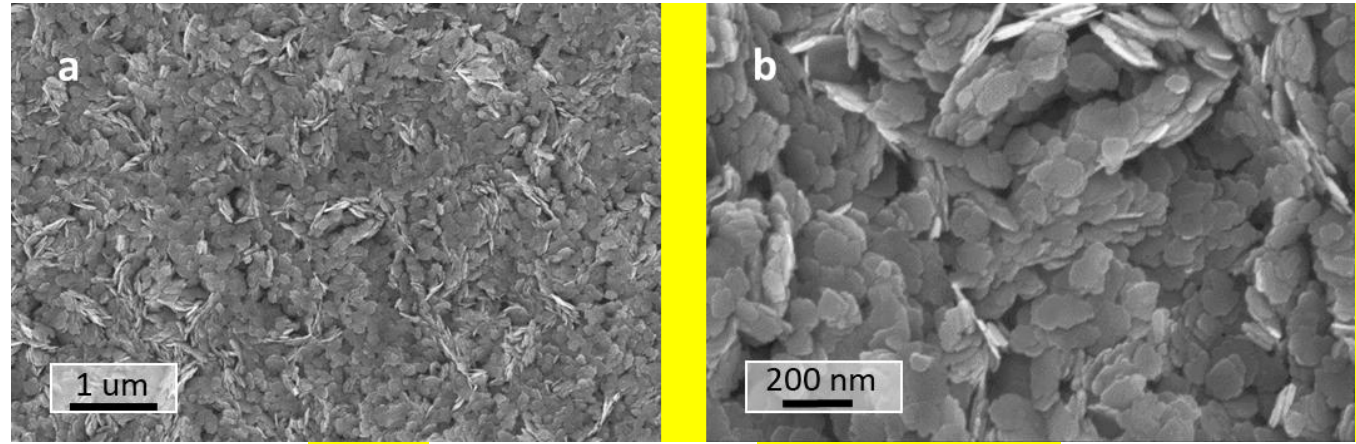

Figure 4. FESEM images of patterns printed depositing one layer

After the printing process, the electrodes were dried during $15 \mathrm{~min}$ on a heating plate at $70^{\circ} \mathrm{C}$. Afterwards they were thermally treated at $325^{\circ} \mathrm{C}$ for one hour under $\mathrm{N}_{2}$ atmosphere (Figure $5 b$ ). This heat treatment was performed in order to achieve the oxidation of the $\mathrm{Ni}(\mathrm{OH})_{2}$ (Figure $5 \mathrm{a}$ ) to $\mathrm{NiO}$ (Figure $5 \mathrm{~b}$ ) and also, to consolidate the nanoplatelets microstructure that will confer the adequate connectivity and robustness to the printed patterns for the use of this ceramic semiconductor structure in energy storage devices.

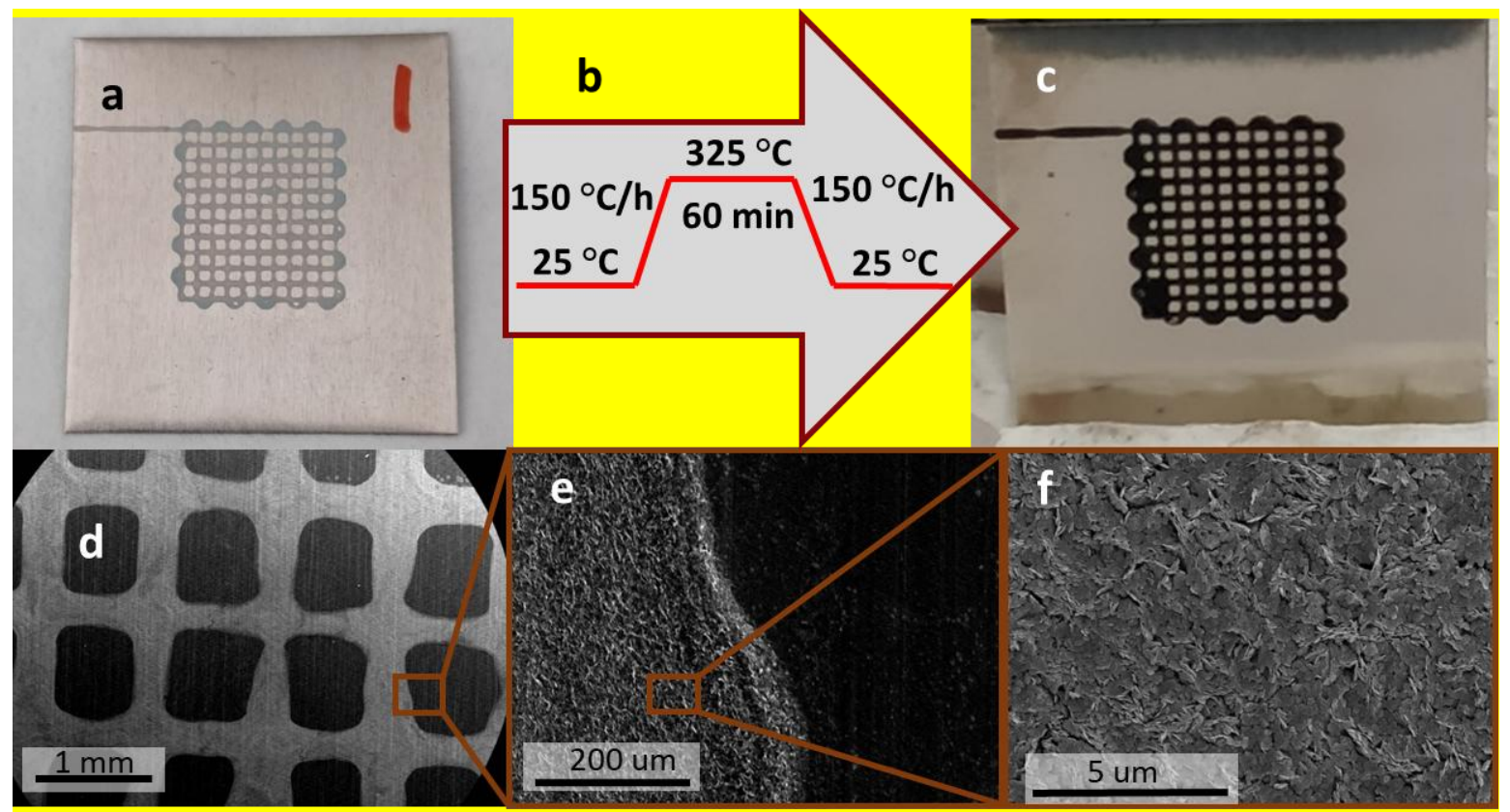

Figure 5. (a-c) Pictures of one layer printed pattern before and after the thermal treatment indicated in (b) and, (d-f) FESEM images of the sintered electrode at different magnifications.

The structure of the designed pattern shows a continuous network not completely homogeneous (Fig. 5 d) because some lines are slightly thinner and present a curvilinear (not straight) edge (Figure $5 \mathrm{e}$ ). In the Figure $5 \mathrm{f}$, both the crack-free microstructure of the pattern and the sintering necks among $\mathrm{NiO}$ nanoplatelets are evidenced. If we compare the FESEM images in Figures 4, it looks that the surface morphology and the pore size of the 
deposition are preserved after the thermal treatment, while the sintering necks among $\mathrm{NiO}$ nanoplatelets can be observed.

In order to study the $\mathrm{NiO}$ electrodes manufactured by IJP, the electrochemical performance of the sintered coatings were evaluated in terms of faradaic capacity. Figure $6 \mathrm{a}$ shows the cyclic voltammetry $(C V)$ curves performed at different sweep rates $(1,2,5$, and $10 \mathrm{mV} / \mathrm{s})$. The quasi symmetrical rectangle-shapes indicate that the $\mathrm{NiO}$ electrodes have relatively large electric double layer capacitance (EDLC) and only a lower faradaic contribution, even at the slowest applied sweep rate $(1 \mathrm{mV} / \mathrm{s})$, which can be attributed to the following reversible redox reaction:

$$
\mathrm{NiO}+\mathrm{OH}^{-} \leftrightarrow \mathrm{NiOOH}+\mathrm{e}^{-}
$$

In addition, specific capacitance values were also determined by galvanostatic measurements. Figure $6 \mathrm{~b}$ presents the typical charge-discharge (C-D) voltage vs. time plots at a potential ranging $0-0.5 \mathrm{~V}$. The C-D curves are shown for the cycle number 10 and 2000 at 1 and $2 \mathrm{~A} / \mathrm{g}$, respectively. The specific capacitances were calculated from galvanostatic charge/discharge curves (at 1 and $2 \mathrm{~A} / \mathrm{g}$ ) by the equation 4, during 2000 cycles, being 70.4 and $50.4 \mathrm{~F} / \mathrm{g}$ the highest values of capacitance achieved, respectively. Then, the capacitance values were plotted in terms of percentage (figures $6 \mathrm{c}$ and $6 \mathrm{~d}$ ), in order to show the long cycle-life of the electrode.
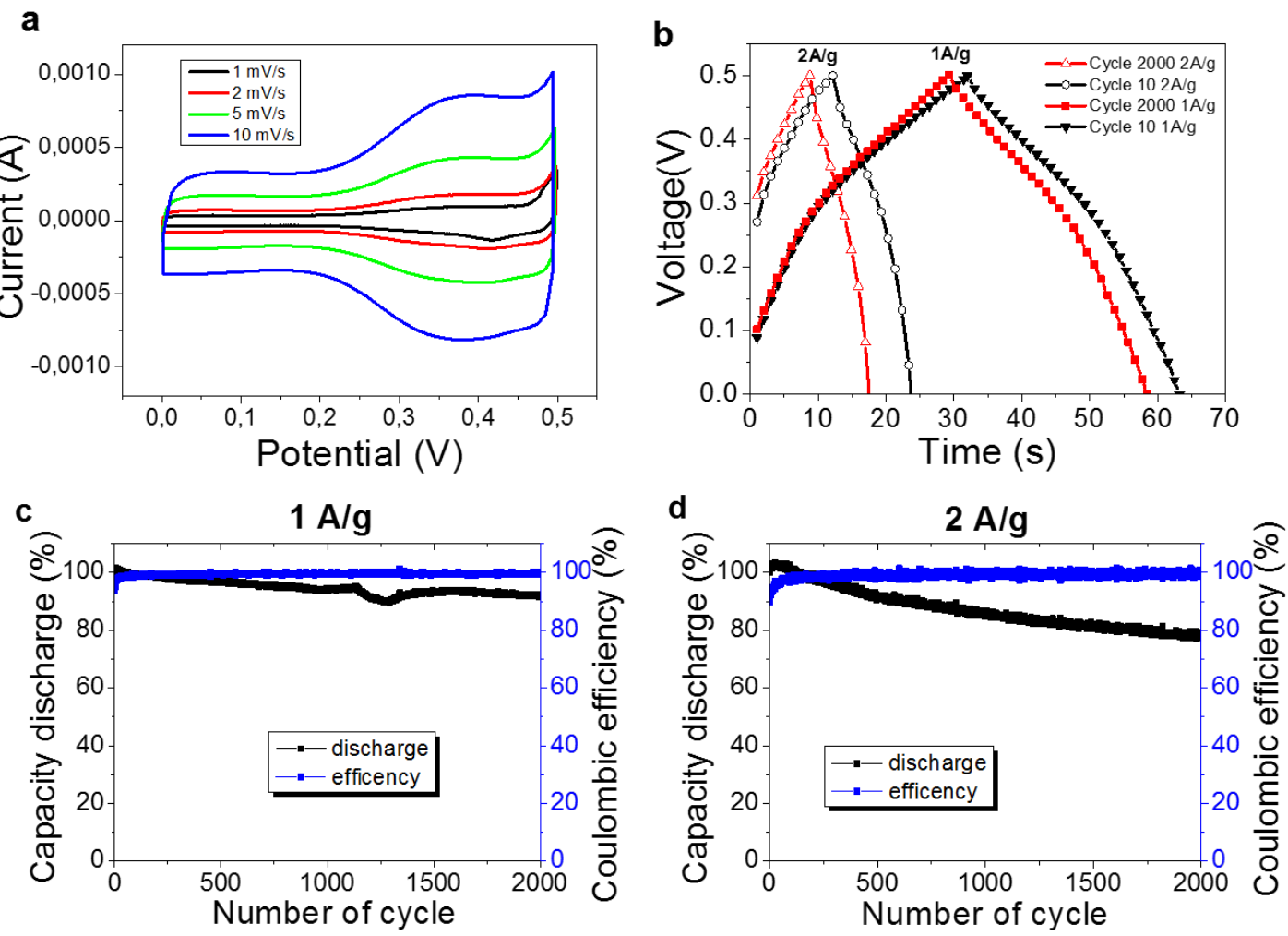

Figure 6. (a) Cyclic voltagrams measured at different scan rates. (b) C-D constant current charge/discharge curves at 1 and $2 \mathrm{~A} / \mathrm{g}$, respectively for the $10^{\text {th }}$ and $2000^{\text {th }}$ 
cycle. (c) \& (d) Specific capacitance retained as a function of number of cycles and the efficiency for 1 and $2 \mathrm{~A} / \mathrm{g}$, respectively.

The good cycling stability evidences the presence of a well-connected semiconductor structure as well as a firmly joined $\mathrm{NiO}$ layer to the $\mathrm{Ni}$ substrate, which facilitates the transport of electrons leading to a $92 \%$ and $78 \%$ of capacitance retention for 2000 cycles at scan rates of 1 and $2 \mathrm{~A} / \mathrm{g}$, respectively. The coulombic efficiency was calculated from the measured charge-discharge curves, as a function of the quotient in percent between the discharge and the charge capacity. The horizontal blue lines in the graphics $6 \mathrm{c}$ and $6 \mathrm{~d}$ show a $100 \%$ coulombic efficiency during thousands of cycles.

The electrochemical performance of IJP NiO patterns was similar to that reported for other $\mathrm{NiO}$ electrodes prepared by other methods [23,27]. Our results suggest that the IJP of $\mathrm{NiO}$ nanoplatelets is a reliable alternative to pattern supercapacitor electrodes with a high resolution. New designs of micro-supercapacitors could printed to increase the exposed surface, providing longer life-cycles and faster charge/discharge cycles than rechargeable micro-batteries [30].

\section{Conclusions}

For the first time it was shown that as-synthetized $\mathrm{Ni}(\mathrm{OH})_{2}$ nanoplatelets dispersed in an aqueous suspension is an useful ink for IJP of ceramic electrodes for pseudocapacitors. The employment of DEG as a co-solvent results in optimal viscosity and surface tension values as well as the ink Z-number. The formulated inks show long time stability and can be used for inkjet printing without any further processing. The waveform function of the piezoelectric nozzle operation was adjusted in order to jet the printable water-based ink. Grid-like printed Ni-based pseudocapacitors electrodes were obtained by IJP. The amount of layers does not affect the morphology and connectivity between the deposited nanoplatelets. A path free of discontinuities with only one layer deposit can be printed, avoiding unnecessary waste of material.

In this work, we show an innovative design of Ni-based electrode obtained by IJP with a subsequent thermal treatment of the printings at $325^{\circ} \mathrm{C}$, which produces electrically conductive TMO electrodes. The electrochemical behavior of $\mathrm{NiO}$ electrodes show a long life during thousands of cycles (92\% of capacitance retention at $1 \mathrm{~A} / \mathrm{g}$ ) and the specific capacitance is comparable to the performance of $\mathrm{NiO}$ electrodes fabricated by traditional techniques. Furthermore, as an additive manufacturing, IJP offers several advantages for environmental health and safety thanks to the reduction of both waste generation and potentially expensive and toxic raw nanomaterials.

\section{Acknowledgment}


The authors thank ECERS grant JECS Trust for funding this project under the contract 2017141, and the support to the projects S2018/NMT-4411 (Comunidad de Madrid) and MAT2015-70780-C4-1 and MAT2017-87541-R (MINECO/FEDER). J. Yus acknowledges the Comunidad de Madrid for the support from the Youth Employment Initiative, CAMPD17_ICV_002. Z. Gonzalez acknowledges the Postdoctoral Fellowship: IJCI-201628538.

\section{Bibliography}

[1] G. Ferrari, P. Zannini, VOCs monitoring of new materials for ceramic tiles decoration: GC-MS analysis of emissions from common vehicles and inkjet inks during firing in laboratory, Bol. La Soc. Esp. Ceram. y Vidr. 56 (2017) 226-236.

[2] R. Cherrington, D.J. Hughes, S. Senthilarasu, V. Goodship, Inkjet-Printed TiO2 Nanoparticles from Aqueous Solutions for Dye-Sensitized Solar Cells (DSSCs), Energy Technol. 3 (2015) 866-870.

[3] B. Derby, Additive Manufacture of Ceramics Components by Inkjet Printing, Engineering. 1 (2015) 113-123.

[4] A. Friederich, C. Kohler, M. Nikfalazar, A. Wiens, M. Sazegar, R. Jakoby, W. Bauer, J.R. Binder, Microstructure and microwave properties of inkjet printed barium strontium titanate thick-films for tunable microwave devices, 34 (2014) 2925-2932.

[5] J.L. Valero, C. Jarom, E. Comas, Optimized Automatic Recovery of Nozzle Health in Inkjet Systems, Program. (2018) 766-770.

[6] M. Arin, P. Lommens, S.C. Hopkins, G. Pollefeyt, J. Van Der Eycken, S. Ricart, X. Granados, B.A. Glowacki, I. Van Driessche, Deposition of photocatalytically active $\mathrm{TiO}_{2}$ films by inkjet printing of $\mathrm{TiO}_{2}$ nanoparticle suspensions obtained from microwave-assisted hydrothermal synthesis, Nanotechnology. 23 (2012).

[7] C. Gadea, Q. Hanniet, A. Lesch, D. Marani, S.H. Jensen, V. Esposito, Aqueous metal-organic solutions for YSZ thin film inkjet deposition, J. Mater. Chem. C. 5 (2017) 6021-6029.

[8] M. Liu, J. Wang, M. He, L. Wang, F. Li, L. Jiang, Y. Song, Inkjet printing controllable footprint lines by regulating the dynamic wettability of coalescing ink droplets, ACS Appl. Mater. Interfaces. 6 (2014) 13344-13348.

[9] F. Zhang, M. Wei, V.V. Viswanathan, B. Swart, Y. Shao, G. Wu, C. Zhou, 3D printing technologies for electrochemical energy storage, Nano Energy. 40 (2017) 418-431.

[10] T. Bakarič, B. Malič, D. Kuscer, Lead-zirconate-titanate-based thick-film structures prepared by piezoelectric inkjet printing of aqueous suspensions, J. Eur. Ceram. Soc. 36 (2016) $4031-$ 4037.

[11] B. Derby, N. Reis, Inkjet Printing of Highly Loaded Particulate Suspensions, MRS Bull. 28 (2003) 815-818.

[12] H.H. Lee, K. Sen Chou, K.C. Huang, Inkjet printing of nanosized silver colloids, Nanotechnology. 16 (2005) 2436-2441.

[13] D. Pech, M. Brunet, P.L. Taberna, P. Simon, N. Fabre, F. Mesnilgrente, V. Conédéra, H. Durou, Elaboration of a microstructured inkjet-printed carbon electrochemical capacitor, J. Power Sources. 195 (2010) 1266-1269.

[14] P. He, B. Derby, Inkjet printing ultra-large graphene oxide flakes, 2D Mater. 4 (2017). 
[15] Y.F. Liu, M.H. Tsai, Y.F. Pai, W.S. Hwang, Control of droplet formation by operating waveform for inks with various viscosities in piezoelectric inkjet printing, Appl. Phys. A Mater. Sci. Process. 111 (2013) 509-516.

[16] H.C. Nallan, J.A. Sadie, R. Kitsomboonloha, S.K. Volkman, Systematic Design of Jettable Nonoparticle-Based Inkjet Rheology, Acoustics, and Jettability, Langmuir. 30 (2014) 1347013477.

[17] M. Bienia, M. Lejeune, M. Chambon, V. Baco-Carles, C. Dossou-Yovo, R. Noguera, F. Rossignol, Inkjet printing of ceramic colloidal suspensions: Filament growth and breakup, Chem. Eng. Sci. 149 (2016) 1-13.

[18] P.E. Delannoy, B. Riou, T. Brousse, J. Le Bideau, D. Guyomard, B. Lestriez, Ink-jet printed porous composite $\mathrm{LiFePO}_{4}$ electrode from aqueous suspension for microbatteries, J. Power Sources. 287 (2015) 261-268.

[19] Y. Gu, A. Wu, H. Sohn, C. Nicoletti, Z. lqbal, J.F. Federici, Fabrication of rechargeable lithium ion batteries using water-based inkjet printed cathodes, J. Manuf. Process. 20 (2015) 198205.

[20] D. Li, D. Sutton, A. Burgess, D. Graham, P.D. Calvert, Conductive copper and nickel lines via reactive inkjet printing, J. Mater. Chem. 19 (2009) 3719-3724.

[21] C.-C. Huang, Z.-K. Kao, Y.-C. Liao, Flexible miniaturized nickel oxide thermistor arrays via inkjet printing technology, ACS Appl. Mater. Interfaces. 5 (2013) 12954-12959.

[22] Y. Rho, K.-T. Kang, D. Lee, Highly crystalline Ni/NiO hybrid electrodes processed by inkjet printing and laser-induced reductive sintering under ambient conditions, Nanoscale. 8 (2016) 8976-8985.

[23] Z. Gonzalez, B. Ferrari, A.J. Sanchez-Herencia, A. Caballero, J. Morales, Relevance of the Semiconductor Microstructure in the Pseudocapacitance of the Electrodes Fabricated by EPD of Binder-Free $\beta-\mathrm{Ni}(\mathrm{OH})_{2}$ Nanoplatelets, J. Electrochem. Soc. 162 (2015) D3001D3012.

[24] S. Cabanas-polo, Z. Gonzalez, A.J. Sanchez-herencia, B. Ferrari, A. Caballero, Cyclability of binder-free $\beta-\mathrm{Ni}(\mathrm{OH})_{2}$ anodes shaped by EPD for Li-ion batteries, J. Eur. Ceram. Soc. 35 (2015) 573-584.

[25] R. Deepak Selvakumar, S. Dhinakaran, Effective viscosity of nanofluids - A modified Krieger-Dougherty model based on particle size distribution (PSD) analysis, J. Mol. Liq. 225 (2017) 20-27.

[26] J. Yus, B. Ferrari, A. Sanchez-Herencia, A. Caballero, J. Morales, Z. Gonzalez, In Situ Synthesis and Electrophoretic Deposition of NiO/Ni Core-Shell Nanoparticles and Its Application as Pseudocapacitor, Coatings. 7 (2017) 193.

[27] Z. Gonzalez, B. Ferrari, A.J. Sanchez-Herencia, A. Caballero, J. Morales, Use of Polyelectrolytes for the Fabrication of Porous NiO Films by Electrophoretic Deposition for Supercapacitor Electrodes, Electrochim. Acta. 211 (2016) 110-118.

[28] P. Sundriyal, S. Bhattacharya, Inkjet-Printed Electrodes on A4 Paper Substrates for LowCost, Disposable, and Flexible Asymmetric Supercapacitors, ACS Appl. Mater. Interfaces. 9 (2017) 38507-38521.

[29] R.D. Deegan, O. Bakajin, T.F. Dupont, G. Huber, S.R. Nagel, T.A. Witten, Capillary flow as the cause of ring stains from dried liquid drops, Nature. 389 (1997) 827-829.

[30] P.H.L. Notten, F. Roozeboom, R.A.H. Niessen, L. Baggetto, 3-D integrated all-solid-state rechargeable batteries, Adv. Mater. 19 (2007) 4564-4567. 
$=$

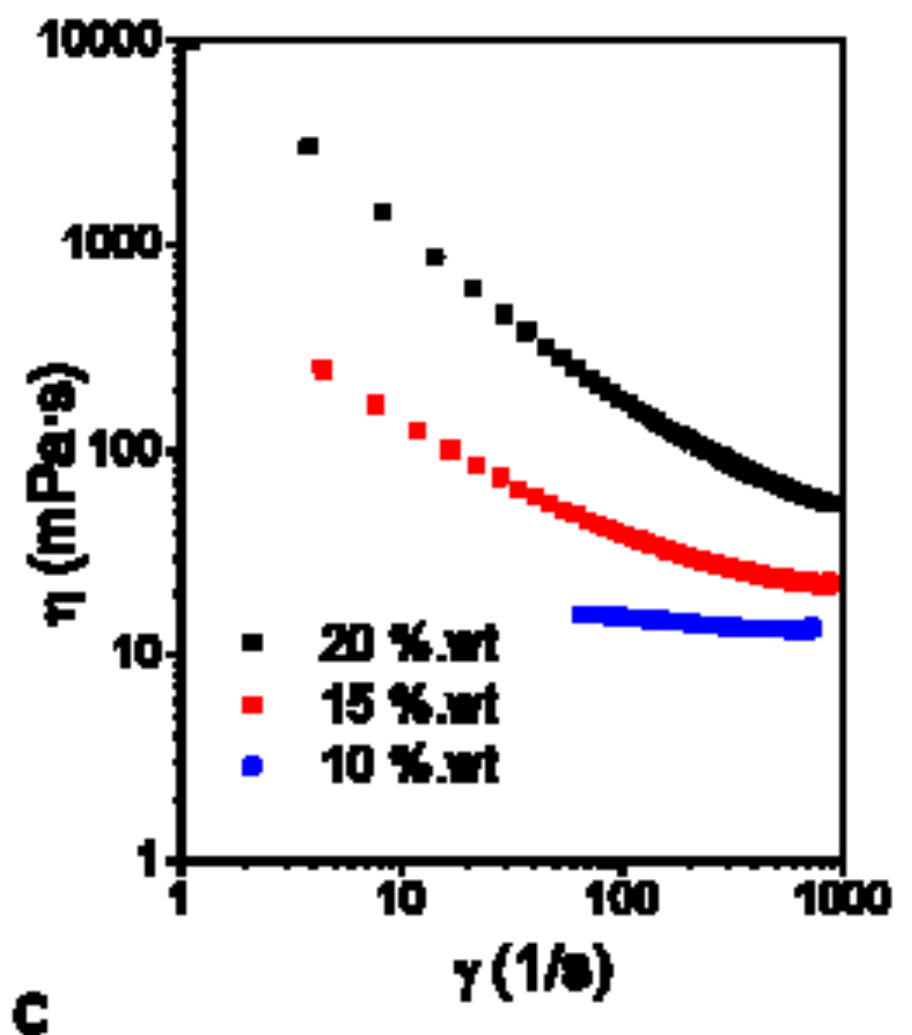

* wt $\mathrm{nkOH})_{2} n$ (nPas) $n$ ( ( Pas)

\begin{tabular}{ccc}
\hline $20 \% w t$ & $3 E 8$ & 43.8 \\
\hline $15 \%$ wt & $1 E 6$ & 18.2 \\
\hline $10 \%$ wt & 16.1 & 13.6
\end{tabular}

b

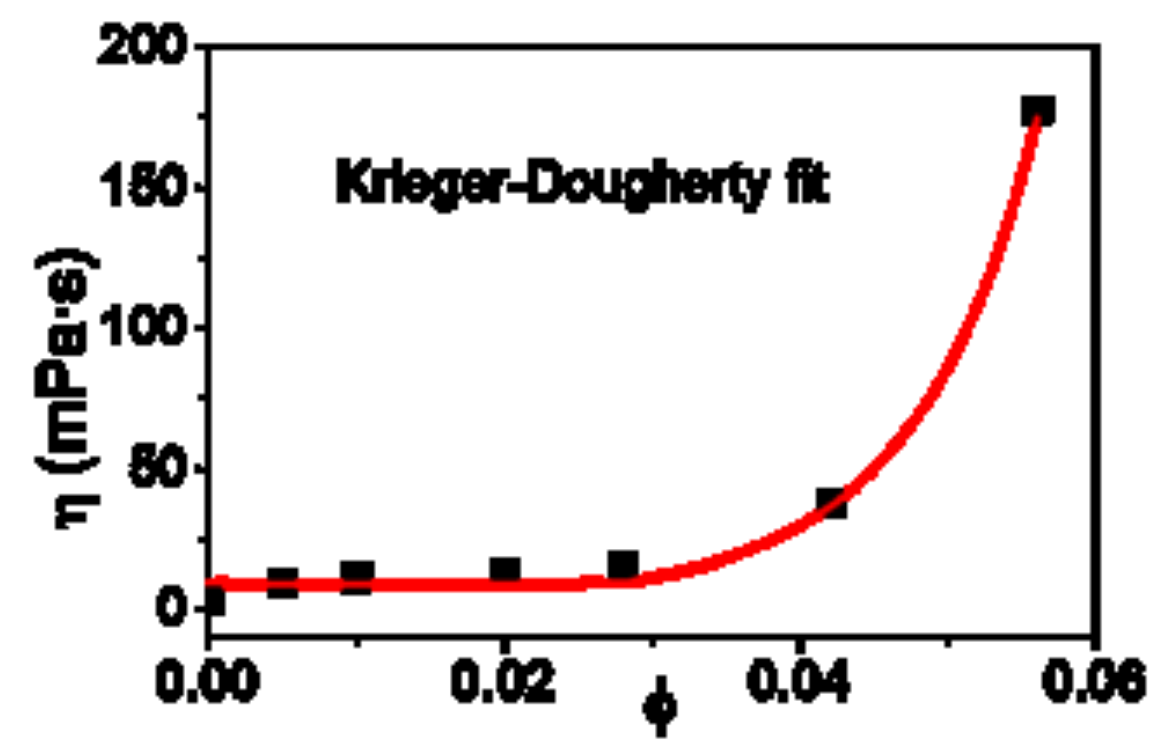

d

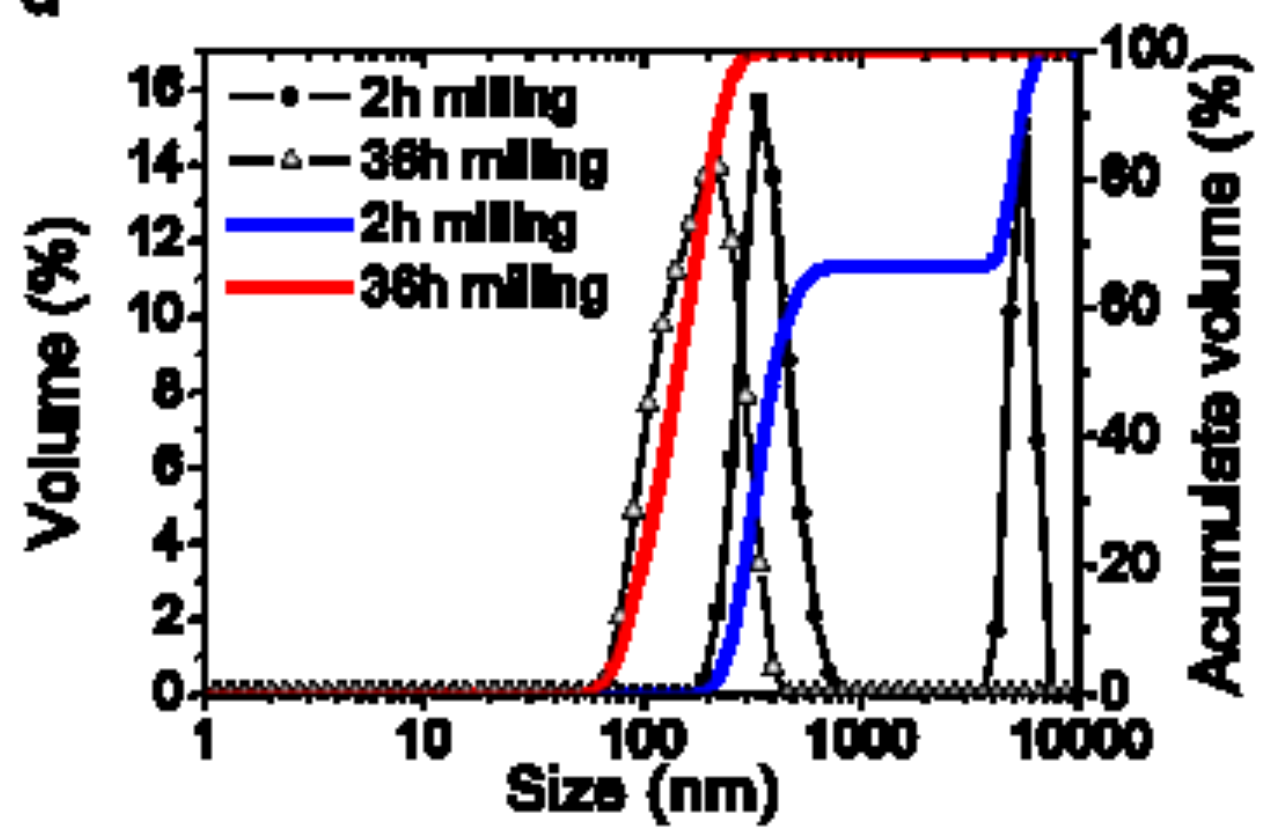


Click here to download high resolution image
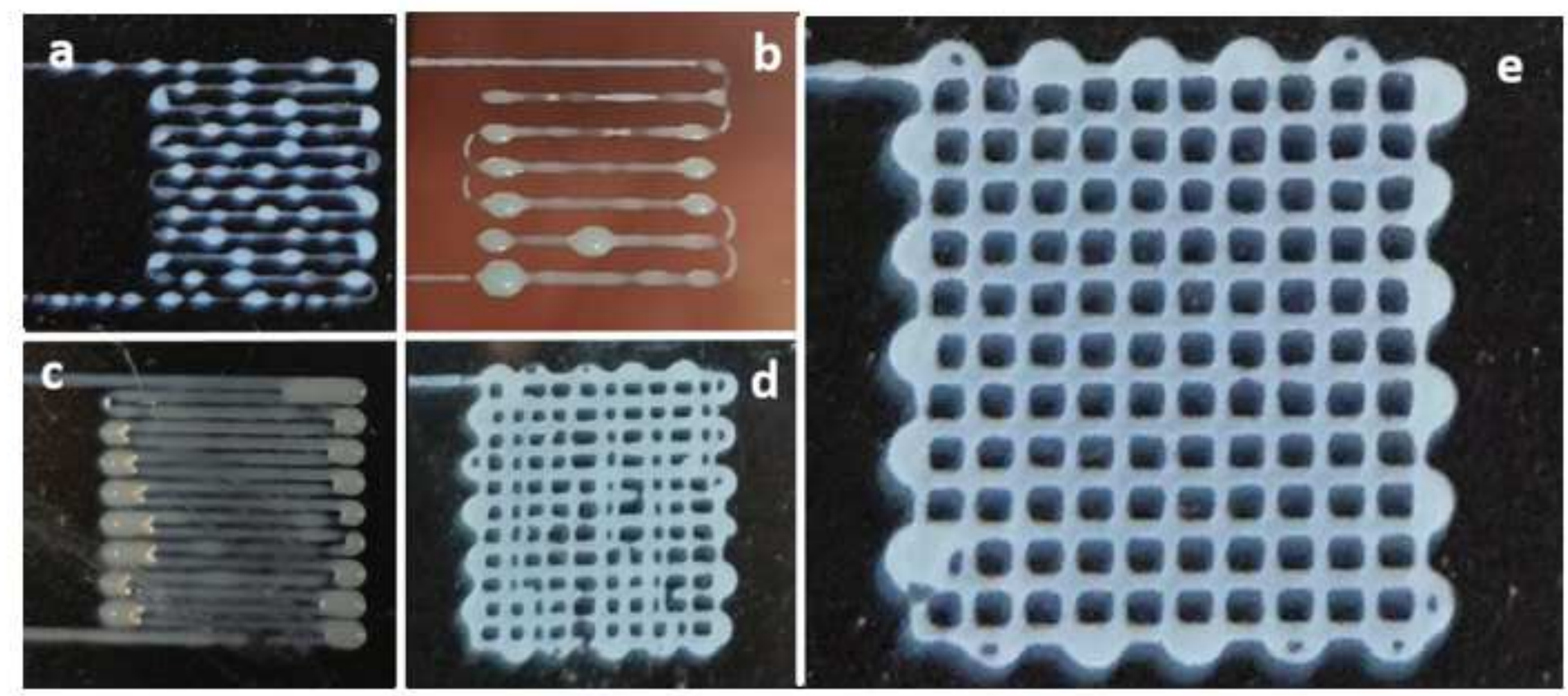

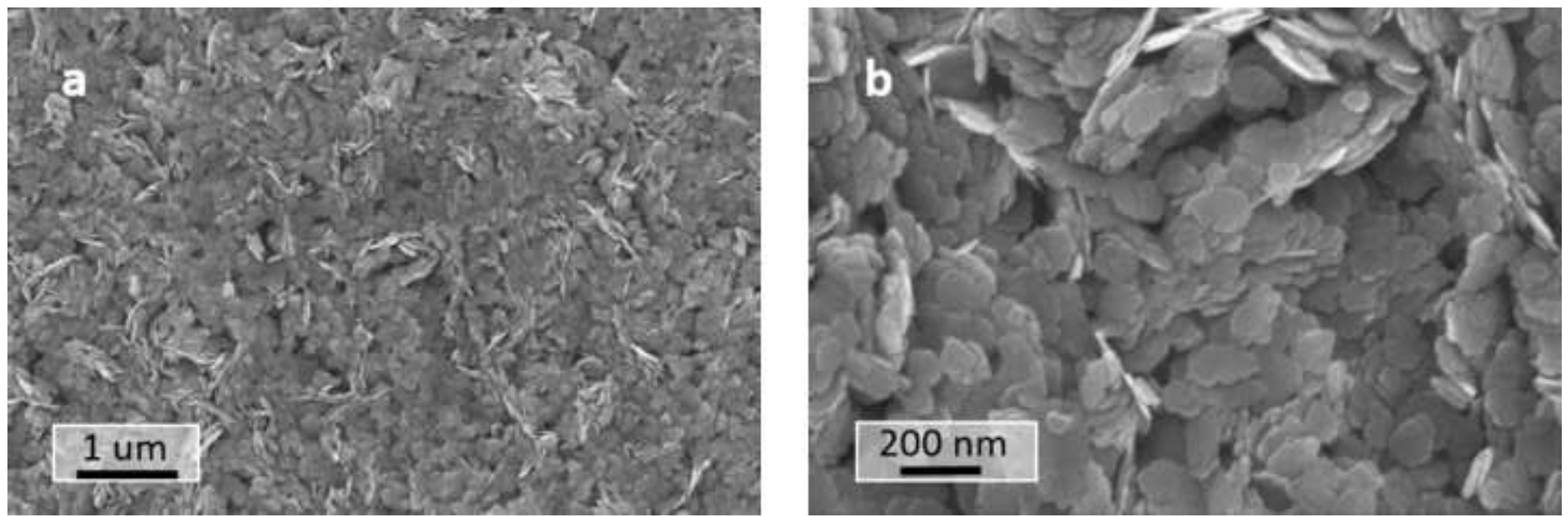
Click here to download high resolution image

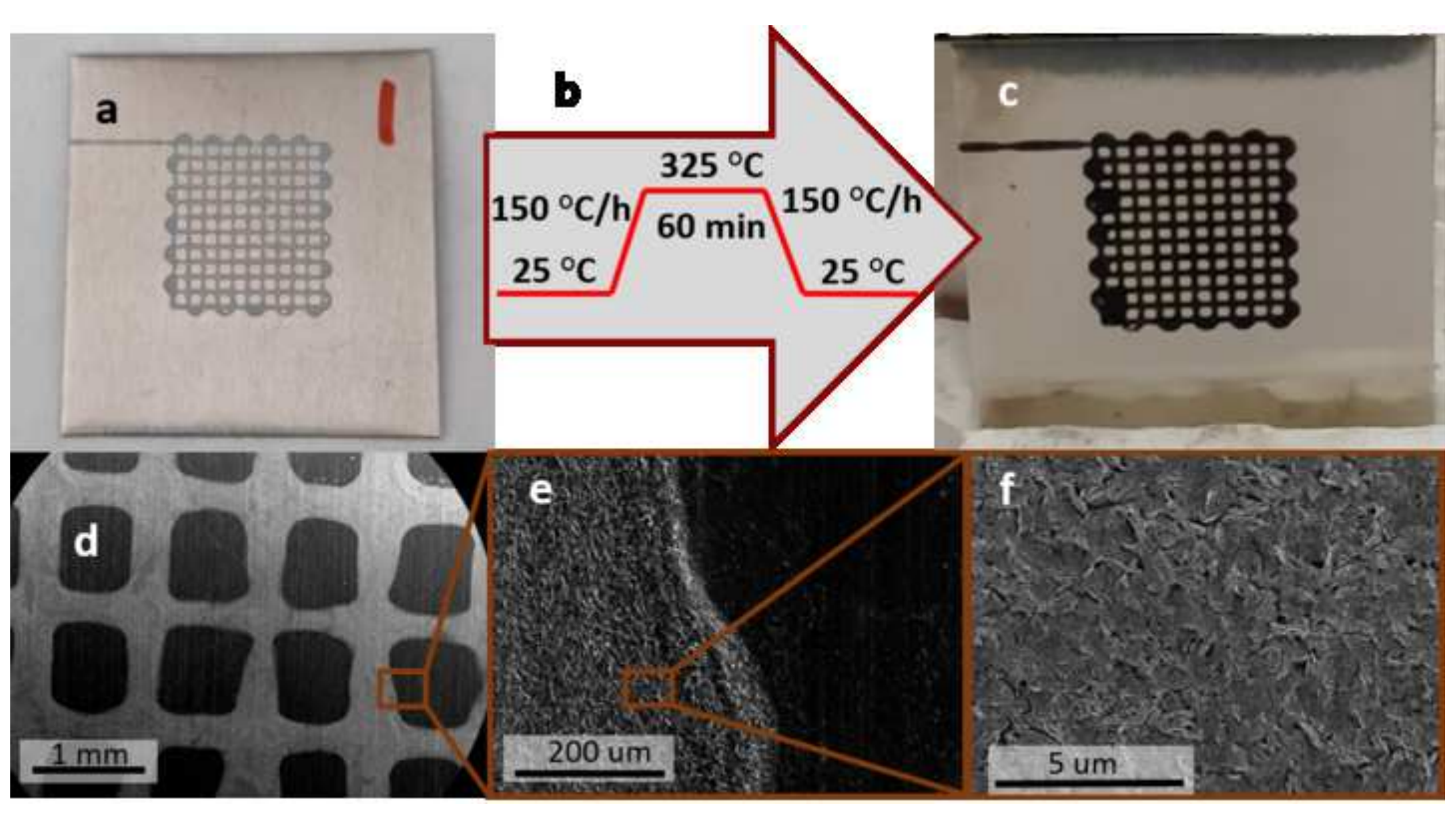

\section{Click here to download high resolution image}


a
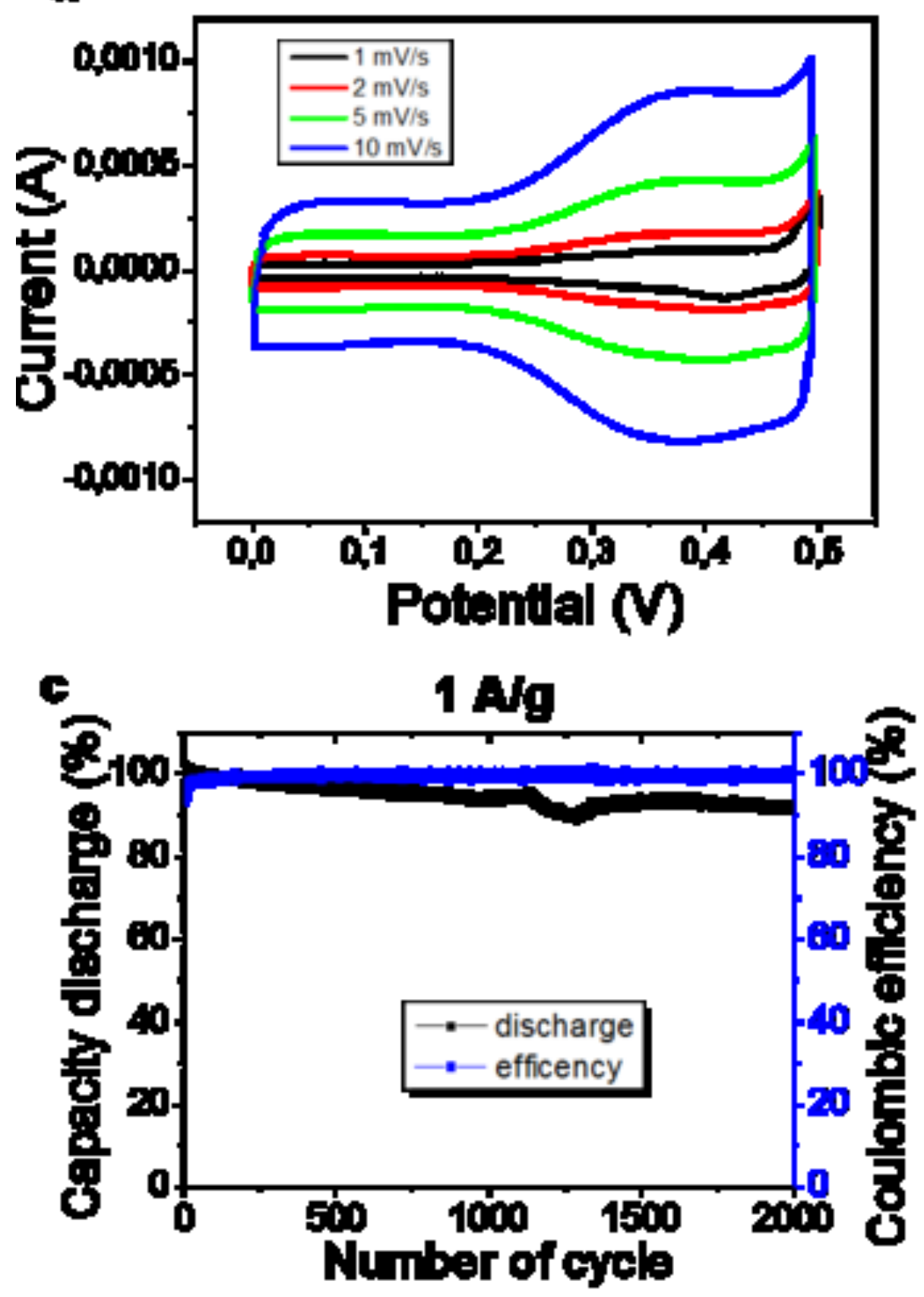

b
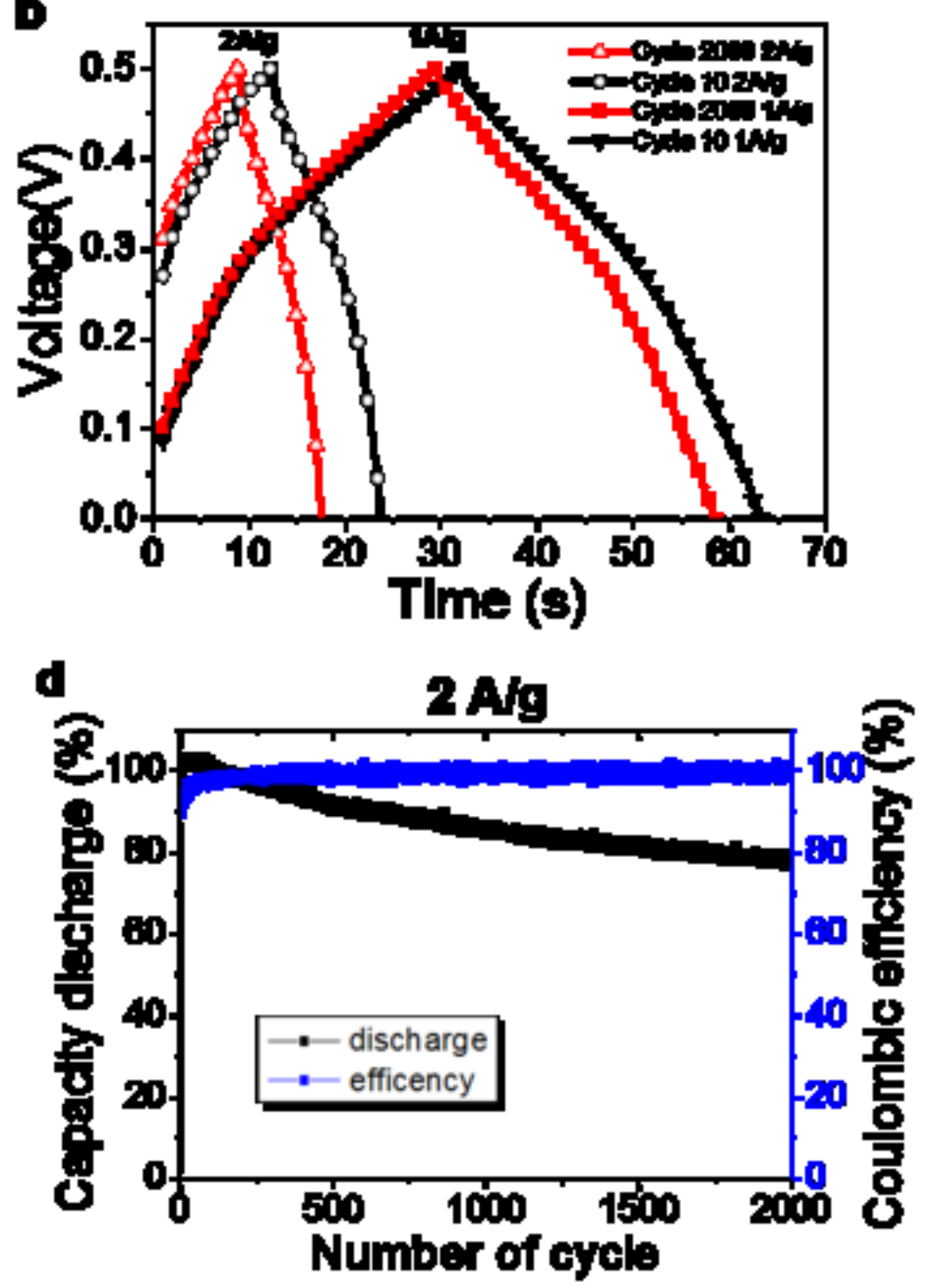
a

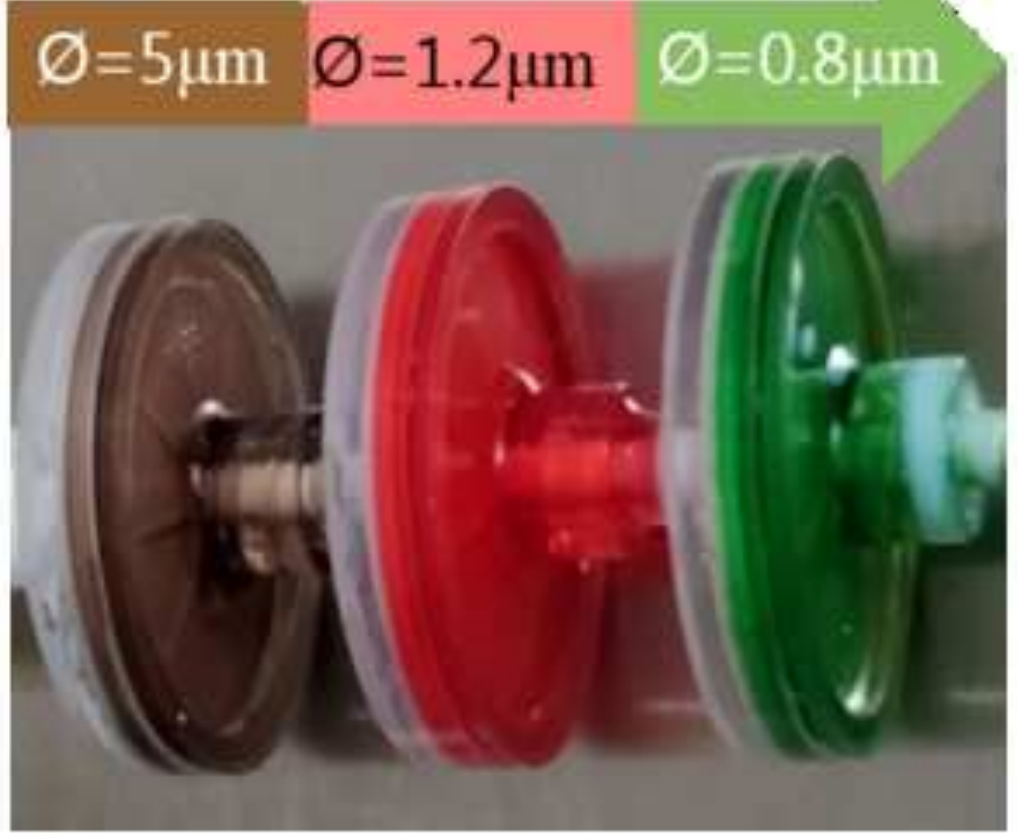

b

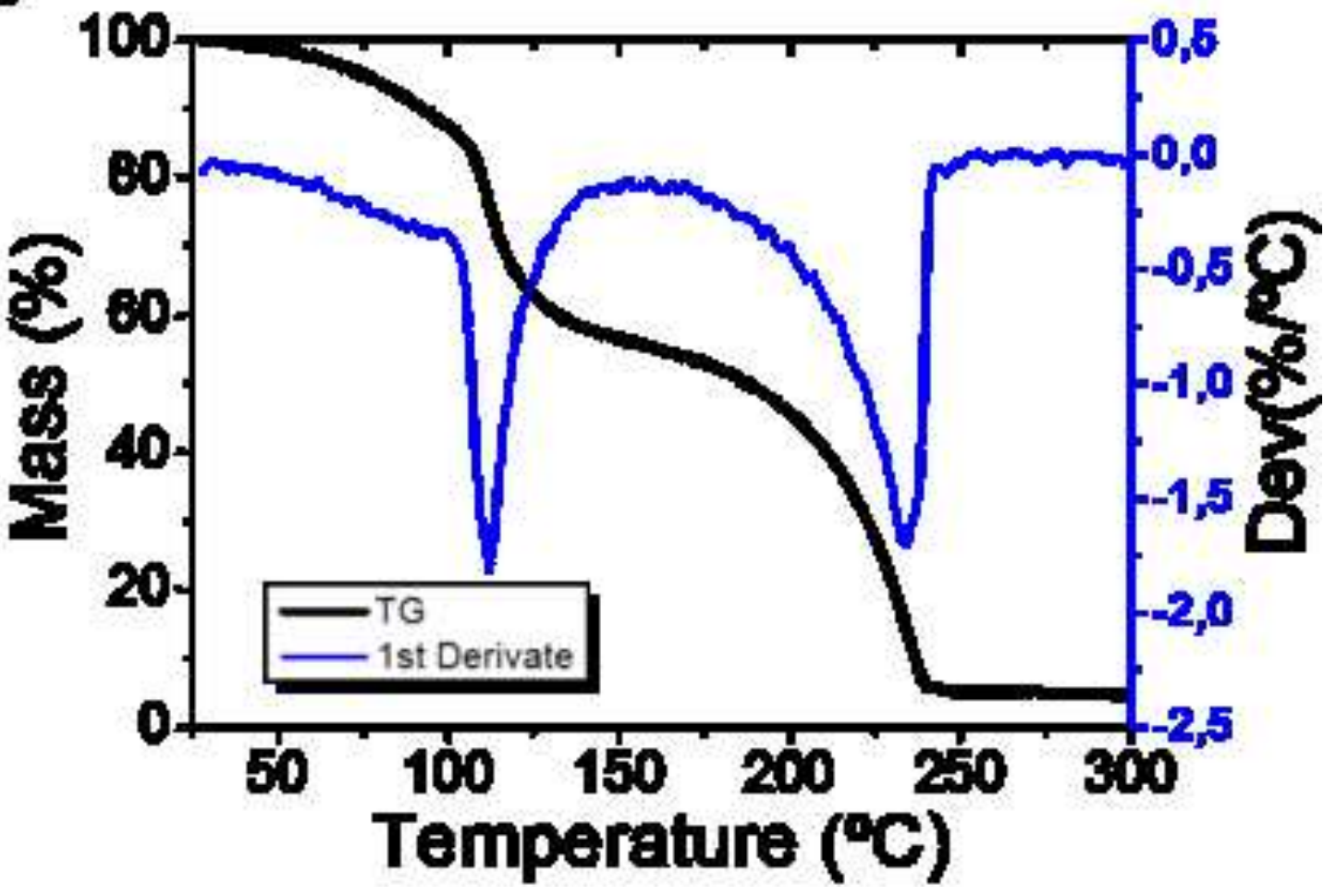



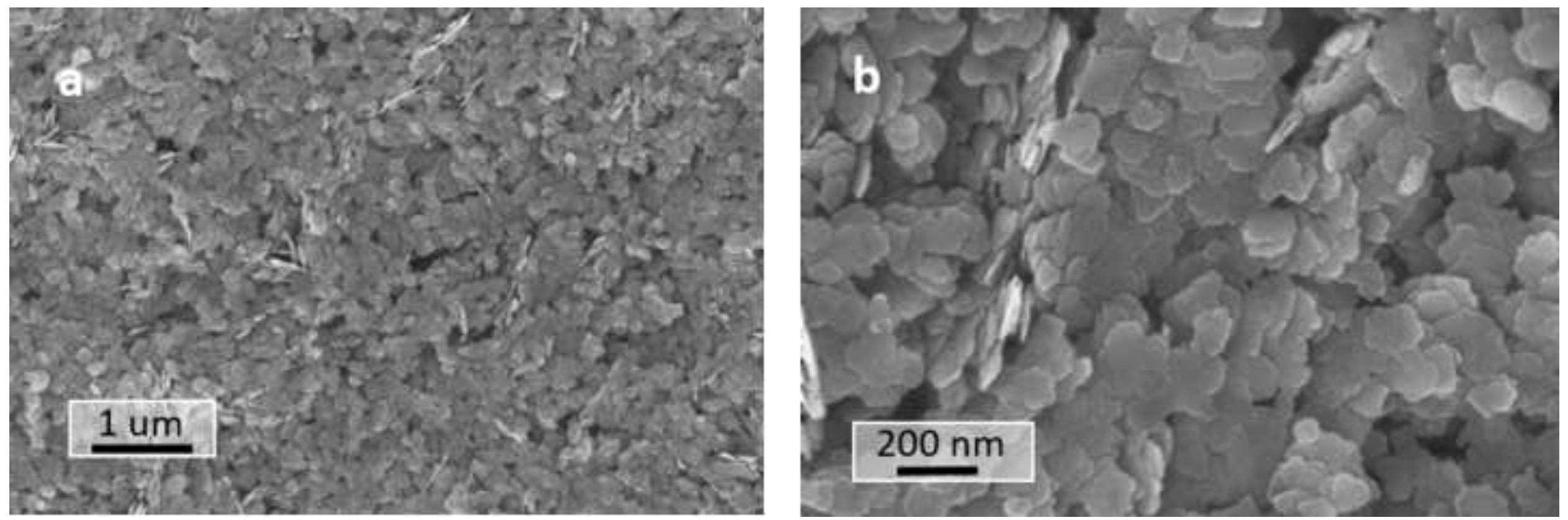
Supplementary Information.

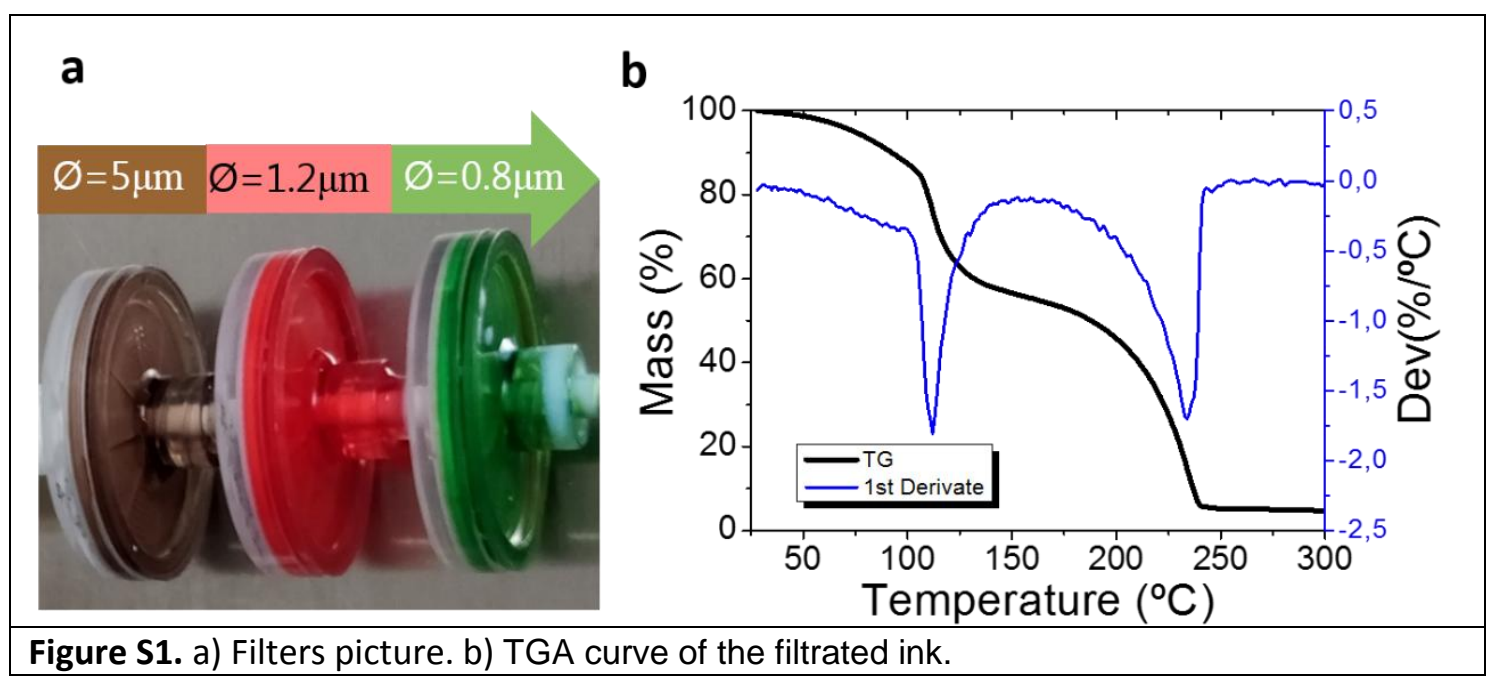

Figure $\mathrm{S} 1 \mathrm{~b}$ shows the TGA analysis of the filtered inks. Two mass losses were evident, one from 80 to $120^{\circ} \mathrm{C}$ and another from 180 to $240^{\circ} \mathrm{C}$ corresponding with the boiling point of the water and DEG, $100^{\circ} \mathrm{C}$ and $245^{\circ} \mathrm{C}$ respectively. Finally, the mass remains lower (7\%wt.) than expected (10\%) after the evaporation of the solvents. This is because a chemical oxidation reaction takes place during the thermal analysis according to the calcination process of the $\mathrm{Ni}(\mathrm{OH})_{2}$ into $\mathrm{NiO}$. The loss of a molecule of water leads to a nominal mass loss of $30 \%$ wt. respect to the mass of the hydroxide. This reaction was detected before $250^{\circ} \mathrm{C}$, and it its confirmed by the final black color of the residue NiO. This result confirms that any significant amount of solid is retained in the filter and $\mathrm{NiO}$ nanoplatelets are fully disperse.

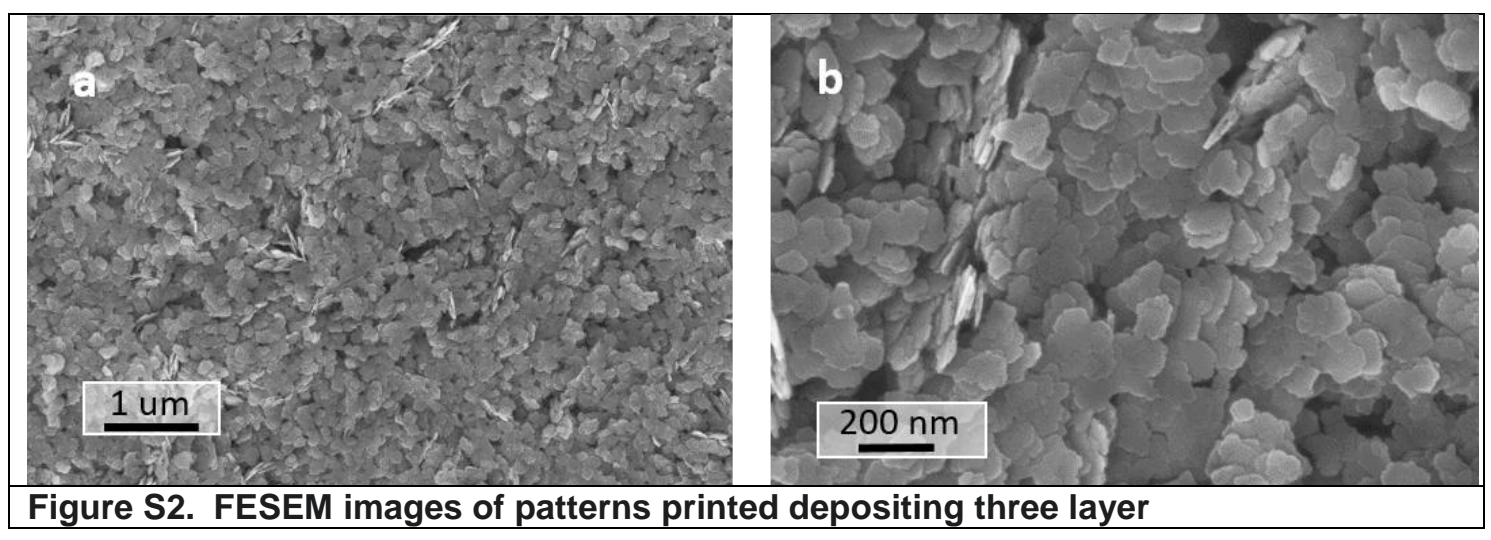

Figure S2. Corresponds with the FESEM images of the 3 layers deposition at different magnifications. The printed patterns show the same microstructure in 
the surface the the one layer deposition. The microstructure, in terms of porosity and morphology looks exactly the same. 